\title{
Can We See the Energy Densities? II. Insights from Linear-Response Time-Dependent Density Functional Theory Calculations ${ }^{\dagger}$
}

\author{
Zheng Pei, ${ }^{a}, \#$ Junjie Yang, ${ }^{b, \#}$ Jingheng Deng, ${ }^{b}$ Yuezhi Mao, ${ }^{c}$ Qin Wu, ${ }^{d}$ Zhibo Yang, ${ }^{b}$ \\ Bin Wang, ${ }^{e}$ Christine M. Aikens, ${ }^{f}$ Wanzhen Liang, ${ }^{* a}$ and Yihan Shao*b
}

Inspired by the analysis of Kohn-Sham energy densities by Nakai et al, we extended the energy density analysis to linear-response time-dependent density functional theory (LR-TDDFT) calculations. Using ethylene-tetrafluoroethylene and oxyluciferin-water complexes as examples, distinctive distribution patterns were demonstrated for the excitation energy densities of local excitations (within a molecular fragment) and charge-transfer excitations (between molecular fragments). It also provided a simple way to compute the effective energy of both hot carriers (particle and hole) from charge-transfer excitations via an integration of the excitation energy density over the donor and acceptor grid points.

\section{Introduction}

Wavefunction analysis has been a central component of electronic structure calculations, dating back to the dawn of modern quantum chemistry. To characterize the charge density distribution of electronic ground state, numerous population schemes were developed to extract atomic (or fragment) charges from the oneparticle density matrix, the electronic density, or the total electrostatic potential. ${ }^{11-3]}$ These include Mulliken partitioning, ${ }^{4]}$ Löwdin partitioning, ${ }^{516}$ atoms-in-molecule partitioning, ${ }^{, 7-19}$ natural population analysis, 10,12 electrostatic-potential-derived charges, 13,22 Becke-weight-based partitioning, ${ }^{23}$ Hirshfeld partitioning, 24, 26 fragment-based Hirshfeld partitioning, 27 iterative Hirshfeld partitioning, 28 it iterative Stockholder atoms partitioning,

\footnotetext{
a State Key Laboratory of Physical Chemistry of Solid Surfaces, Collaborative Innovation Center of Chemistry for Energy Materials, Fujian Provincial Key Laboratory of Theoretical and Computational Chemistry, and Department of Chemistry, College of Chemistry and Chemical Engineering, Xiamen University, Xiamen 361005, P. R. China. E-mail: liangwz@xmu.edu.cn

${ }^{b}$ Department of Chemistry and Biochemistry, University of Oklahoma, 101 Stephenson Pkwy, Norman, OK 73019, United States. E-mail: yihan.shao@ou.edu

c Department of Chemistry, Stanford University, Stanford, CA 94305, United States.

${ }^{d}$ Center for Functional Nanomaterials, Brookhaven National Laboratory, Upton, NY 11973, United States.

e Center for Interfacial Reaction Engineering and School of Chemical, Biological, and Materials Engineering, Gallogly College of Engineering, University of Oklahoma, Norman, OK 73019, United States.

${ }^{f}$ Department of Chemistry, Kansas State University, Manhattan, KS 66506, United States.

\# These two authors contributed equally to this work.

$\dagger$ Electronic Supplementary Information (ESI) available: [details of any supplementary information available should be included here]. See DOI: 00.0000/00000000.
}

tended Hirshfeld partitioning, ${ }^{34}$ density derived electrostatic and chemical charges, ${ }^{35,}, 39$ charge models I through $\mathrm{V},{ }^{[140141]}$ etc. Relatedly, Fukui functions (i.e. atomic population changes upon electron detachment/attachment) ${ }^{42 / 44}$ were also developed to gauge the site reactivity of organic compounds.

Most of these ground-state atomic population schemes can be readily extended to excited-state calculations to analyze the excited-state electron density, as well as the corresponding attachment, detachment, and transition densities. ${ }^{45 / 47}$ Furthermore, several metrics based on the excited-state wavefunction ${ }^{48 / 57}$ (especially the $\Lambda$ value from Peach et a ${ }^{[58}$ ) were proposed to distinguish between different types of electronic excitations (i.e., local, charge transfer, and Rydberg excitations) of molecular complexes or extended molecules. Recently, the exciton (particle-hole pair) concept from solid state physics perspective was also adopted by Dreuw et al to distinguish and characterize different excitation types and extract their relevant properties. .5960

During an electron excitation, the molecular system not only undergoes a charge density distribution, which is described by the detachment (hole) and attachment (particle) densities, ${ }^{61}$ but also experiences a substantial increase in the total energy (a.k.a. the excitation energy). Conceptually, it is appealing to consider how the excitation energy is distributed within the molecule. Intuitively, we expect a map of the excitation energy density (i.e. a real-space distribution of the excitation energy) would show substantially increased energy density around the hole (because it requires energy to remove an electron from occupied orbitals) and possibly around the particle (if energy is needed to inject an electron into unoccupied orbitals). An integration of the excitation energy density 
around (well-separated) hole/particle will thus yield the effective energies of both the hole and particle. These effective energies could be quite valuable in the modeling of hole-particle pairs in photochemical processes, such as solar cells, light-emitting devices, plasmon-enhanced spectroscopy, and catalysis, etc.

In contrast to the much-developed charge density analysis, however, much less effort has been devoted to the grid-based energy distribution for electronic ground and excited states. As a matter of fact, the only work we are aware of in this direction is a gridbased atomic energy partitioning scheme by Nakai et al, who used it to decompose the total Kohn-Sham density functional theory (KS-DFT) energy into atomic and bond energy components. 62, 64 But it is rather straightforward to extend Nakai et al's grid-based energy partitioning scheme to the analysis of the excitation energy distribution within the linear-response time-dependent density functional (LR-TDDFT) framework. ${ }^{65}$ Such an extension will be reported below in this article.

An interesting question here is: is the excitation energy density uniquely defined? Needless to say, the computed LR-TDDFT excitation energy density map of a molecular system would depend on the choices of the density functional, basis set, and numerical integration grid (for solving KS-DFT and LR-TDDFT equations and for evaluating the energy density). Given a combination of functional/basis/grid, however, only one component of the excitation energy density is found to be not uniquely defined within our formulation. It corresponds to the two-electron Hartree-Fock exchange energy (i.e. the electrostatic interaction between the hole-particle pair shown later in Eqs. 28 and 29], and we choose to split its contributions evenly between the hole and particle.

This article is organized as follows. In the next section, we will briefly review Nakai et al's scheme for computing grid-based KS-DFT energy density, and then formulate our extension of this scheme for evaluating and partitioning LR-TDDFT excitation energy density. Results and discussions will be provided in Sections 3 and 4 for two model complexes $\left(\mathrm{C}_{2} \mathrm{H}_{4}-\mathrm{C}_{2} \mathrm{~F}_{4}\right.$ and OLH- $\left.\mathrm{H}_{2} \mathrm{O}\right)$. Concluding remarks will be presented in Section 5.

This article complements an accompanying report, where an analysis of energy densities from a real-time time-dependent density functional theory (RT-TDDFT) simulation ${ }^{70}$ was presented.

\section{Methods}

In this work, all occupied Kohn-Sham orbitals (labeled as $i$ and $j$ ), and virtual orbitals (labeled as $a$ and $b$ ) are assumed to be all real. They are linear combinations of atom-centered Gaussian basis functions (labelled as $\mu, v, \lambda$, and $\sigma$ ),

$$
\begin{aligned}
\psi_{i}(\boldsymbol{r}) & =\sum_{\mu} C_{\mu i} \phi_{\mu}(\boldsymbol{r}) \\
\psi_{a}(\boldsymbol{r}) & =\sum_{\mu} C_{\mu a} \phi_{\mu}(\boldsymbol{r})
\end{aligned}
$$

with $\mathbf{C}_{\mathrm{o}}$ and $\mathbf{C}_{\mathrm{v}}$ collectively representing the respective molecular orbital coefficients. The ground-state one-particle density matrix is $\mathbf{P}=\mathbf{C}_{0} \mathbf{C}_{0}^{\dagger}$, namely

$$
P^{\mu v}=\sum_{i} C_{\mu i} C_{v i}
$$

and the corresponding electron density is

$$
\rho(\mathbf{r})=\sum_{i}\left|\psi_{i}(\mathbf{r})\right|^{2}=\sum_{\mu v} P^{\mu v} \phi_{\mu}(\boldsymbol{r}) \phi_{v}(\boldsymbol{r}) .
$$

\subsection{Grid-Based KS-DFT Ground State Energy Density}

The ground-state KS-DFT energy is known to contain several components,

$$
\begin{aligned}
E_{0} & =\left(E^{T}+E^{N}\right)+\left(E^{J}+E^{K}\right)+E^{X C} \\
& =\mathbf{P} \cdot \mathbf{h}+\frac{1}{2} \mathbf{P} \cdot \boldsymbol{\Pi} \cdot \mathbf{P}+\int f_{x c}(\rho(\boldsymbol{r})) d \mathbf{r}
\end{aligned}
$$

with the core Hamiltonian (h) - kinetic (T) and nuclear attraction (N) - being

$$
E^{T}+E^{N}=\sum_{\mu v} P^{\mu v} \int \phi_{\mu}(\boldsymbol{r})\left[-\frac{1}{2} \nabla^{2}-\sum_{A} \frac{Z_{A}}{|\boldsymbol{r}-\boldsymbol{A}|}\right] \phi_{v}(\boldsymbol{r}) d \boldsymbol{r}
$$

where $Z_{A}$ and $\boldsymbol{A}$ are the nuclear charge and coordinates of the $A$-th atom, respectively. The Coulomb $(\mathrm{J})$ and Hartree-Fock exchange (K) energies are,

$$
E^{J}+E^{K}=\frac{1}{2} \mathbf{P} \cdot \boldsymbol{\Pi} \cdot \mathbf{P}=\frac{1}{2} \sum_{\mu \nu, \lambda \sigma} P^{\mu \nu}\left[(\mu \nu \mid \lambda \sigma)-\alpha_{K}(\mu \lambda \mid v \sigma)\right] P^{\lambda \sigma}
$$

where $\alpha_{K}$ is the ratio of Hartree-Fock exchange for conventional hybrid functionals and the two-electron repulsion integrals are

$$
\begin{aligned}
& (\mu \nu \mid \lambda \sigma)=\iint \phi_{\mu}(\boldsymbol{r}) \phi_{v}(\boldsymbol{r}) \frac{1}{\left|\boldsymbol{r}-\boldsymbol{r}^{\prime}\right|} \phi_{\lambda}\left(\boldsymbol{r}^{\prime}\right) \phi_{\sigma}\left(\boldsymbol{r}^{\prime}\right) d \boldsymbol{r} d \boldsymbol{r}^{\prime} \\
& (\mu \lambda \mid \nu \sigma)=\iint \phi_{\mu}(\boldsymbol{r}) \phi_{\lambda}(\boldsymbol{r}) \frac{1}{\left|\boldsymbol{r}-\boldsymbol{r}^{\prime}\right|} \phi_{\nu}\left(\boldsymbol{r}^{\prime}\right) \phi_{\sigma}\left(\boldsymbol{r}^{\prime}\right) d \boldsymbol{r} d \boldsymbol{r}^{\prime}
\end{aligned}
$$

Note that, for range-separated functionals, the Coulomb operator in Eq. 9 will be replaced with a linear combination of short-range and long-range operators.

With most quantum chemistry programs, the kinetic, nuclear attraction, Coulomb, and Hartree-Fock energy components would be calculated analytically. But, as shown by Nakai et al, like the exchange-correlation energy in Eq. 5, an energy density can also be defined for each of all other energy components,

$$
\rho_{0}^{E}(\mathbf{r})=\rho_{0}^{T}(\mathbf{r})+\rho_{0}^{N}(\mathbf{r})+\rho_{0}^{J}(\mathbf{r})+\rho_{0}^{K}(\mathbf{r})+f_{x c}(\rho(\boldsymbol{r}))
$$

which together integrate into the total KS-DFT energy in Eq. 5

$$
E_{0}=\int \rho_{0}^{E}(\mathbf{r}) d \mathbf{r}
$$

The kinetic energy density is well known to be,

$$
\rho_{0}^{T}(\mathbf{r})=\frac{1}{2} \sum_{\mu v} P^{\mu v}\left(\nabla \phi_{\mu}(\mathbf{r})\right) \cdot\left(\nabla \phi_{v}(\mathbf{r})\right)
$$

whereas the nuclear attraction energy density is simply the product 
of the electron density and the nuclear electrostatic potential

$$
\rho_{0}^{N}(\mathbf{r})=-\rho(\mathbf{r}) \sum_{A} \frac{Z_{A}}{|\mathbf{r}-\mathbf{A}|} .
$$

Once the grid value of electrostatic potential of each pair of atomic basis functions

$$
V_{\lambda \sigma}(\mathbf{r})=\int \frac{\phi_{\lambda}\left(\mathbf{r}^{\prime}\right) \phi_{\sigma}\left(\mathbf{r}^{\prime}\right)}{\left|\mathbf{r}-\mathbf{r}^{\prime}\right|} d \mathbf{r}^{\prime}
$$

is pre-computed, one can readily obtain the Coulomb $(J)$ and Hartree-Fock exchange $(K)$ energy densities in three steps ,

$$
\begin{aligned}
\rho_{0}^{J}(\mathbf{r}) & =-\rho(\mathbf{r}) V(\mathbf{r})=\left[\sum_{\mu v} P^{\mu v} \phi_{\mu}(\mathbf{r}) \phi_{v}(\mathbf{r})\right]\left[\sum_{\lambda \sigma} V_{\lambda \sigma}(\mathbf{r}) P^{\lambda \sigma}\right] \\
\rho_{0}^{K}(\mathbf{r}) & =-\alpha_{K} \sum_{\mu v, \lambda \sigma} \phi_{\mu}(\mathbf{r}) \phi_{\lambda}(\mathbf{r}) V_{v \sigma}(\mathbf{r}) P^{\mu v} P^{\lambda \sigma} \\
& =-\alpha_{K} \sum_{v \sigma}\left[\sum_{\mu} P^{\mu v} \phi_{\mu}(\mathbf{r})\right] V_{v \sigma}(\mathbf{r})\left[\sum_{\lambda} P^{\lambda \sigma} \phi_{\lambda}(\mathbf{r})\right]
\end{aligned}
$$

where $V(\mathbf{r})=-\sum_{\lambda \sigma} V_{\lambda \sigma}(\mathbf{r}) P^{\lambda \sigma}$ is the electrostatic potential of the total electron density. While the costs of computing $V_{\lambda \sigma}(\mathbf{r})$, $V(\mathbf{r}), \sum_{\mu} P^{\mu v} \phi_{\mu}(\mathbf{r})$, and $\rho_{0}^{K}(\mathbf{r})$ all scale as $\mathrm{O}\left(N_{\text {bas }}^{2} N_{\text {grid }}\right)$, the most expensive term is $V_{\lambda \sigma}(\mathbf{r})$ because it takes more FLOPS to evaluate one-electron integrals than to perform matrix multiplications.

\subsection{Grid-Based LR-TDDFT Excitation Energy Density}

Within the RT-TDDFT framework, the (unrelaxed) difference density matrix $\left(\mathbf{P}_{\omega}\right)$ and transition density matrix $\left(\mathbf{R}_{\omega}\right)$ are defined from the transition amplitudes ( $\mathbf{X}$ and $\mathbf{Y}$, each of dimension $\left.N_{\mathrm{V}} \times N_{\mathrm{O}}\right), 73$

$$
\begin{aligned}
\mathbf{P}_{\omega} & =\mathbf{P}_{\omega}^{\text {attach }}-\mathbf{P}_{\omega}^{\text {detach }} \\
& =\mathbf{C}_{\mathrm{v}}\left(\mathbf{X} \mathbf{X}^{\dagger}+\mathbf{Y} \mathbf{Y}^{\dagger}\right) \mathbf{C}_{\mathrm{v}}^{\dagger}-\mathbf{C}_{\mathrm{o}}\left(\mathbf{X}^{\dagger} \mathbf{X}+\mathbf{Y}^{\dagger} \mathbf{Y}\right) \mathbf{C}_{\mathrm{o}}^{\dagger} \\
\mathbf{R}_{\omega} & =\mathbf{C}_{\mathrm{V}} \mathbf{X} \mathbf{C}_{\mathrm{o}}^{\dagger}+\mathbf{C}_{\mathrm{o}} \mathbf{Y}^{\dagger} \mathbf{C}_{\mathrm{v}}^{\dagger}
\end{aligned}
$$

of each excited state. Note that $\mathbf{P}_{\omega}$ is a symmetric matrix, while $\mathbf{R}_{\omega}$ is not. Using these matrices, a compact expression for the excitation energy is,, 74

$$
\omega=\mathbf{P}_{\omega} \cdot \mathbf{F}+\mathbf{R}_{\omega} \cdot(\boldsymbol{\Pi}+\boldsymbol{\Omega}) \cdot \mathbf{R}_{\omega}
$$

where $\mathbf{F}$ is the ground-state Fock matrix. Here, $\boldsymbol{\Omega}$ is the exchangecorrelation portion of the Kohn-Sham response kernel

$$
\Omega_{\mu v, \lambda \sigma}=\frac{\partial F_{\mu \nu}^{\mathrm{xc}}}{\partial P^{\lambda \sigma}}=\int\left(\sum_{\xi, \xi^{\prime}} \frac{\partial^{2} f_{\mathrm{xc}}}{\partial \xi \partial \xi^{\prime}} \frac{\partial \xi}{\partial P^{\mu v}} \frac{\partial \xi^{\prime}}{\partial P^{\lambda \sigma}}\right) d \mathbf{r}
$$

with $\xi$ and $\xi^{\prime}$ referring to alpha and beta electron densities $\left(\rho_{\sigma}\right)$ and their gradient components $\left(\rho_{\sigma}^{x}, \rho_{\sigma}^{y}\right.$, and $\left.\rho_{\sigma}^{z}\right)$. We shall call the $\mathbf{P}_{\omega} \cdot \mathbf{F}$ term in Eq. 19, which arises from orbital energy differences, the one-electron contribution to the excitation energy. The $\mathbf{R}_{\omega} \cdot(\boldsymbol{\Pi}+\boldsymbol{\Omega}) \cdot \mathbf{R}_{\omega}$ term, on the other hand, will be called twoelectron contributions.

Similar to the ground-state KS-DFT energy, we can distribute the LR-TDDFT excitation energy in Eq. 19 over a real-space grid,

$$
\omega=\int \rho^{\omega}(\mathbf{r}) d \mathbf{r}
$$

with the excitation energy density components being

$$
\rho^{\omega}(\mathbf{r})=\rho^{T}(\mathbf{r})+\rho^{N}(\mathbf{r})+\rho^{J}(\mathbf{r})+\rho^{K}(\mathbf{r})+\rho^{X C}(\mathbf{r}) .
$$

The first two components - kinetic and nuclear attraction energy densities - come only from the one-electron term $\left(\mathbf{P}_{\omega} \cdot \mathbf{F}\right)$

$$
\begin{aligned}
& \rho^{T}(\mathbf{r})=\frac{1}{2} \sum_{\mu, v, i} P_{\omega}^{\mu v}\left(\nabla \phi_{\mu}(\mathbf{r})\right) \cdot\left(\nabla \phi_{v}(\mathbf{r})\right) \\
& \rho^{N}(\mathbf{r})=-\rho_{\text {diff }}(\mathbf{r}) \sum_{A} \frac{Z_{A}}{|\mathbf{r}-\mathbf{A}|}
\end{aligned}
$$

where the (unrelaxed) difference density is

$$
\rho_{\mathrm{diff}}(\mathbf{r})=\sum_{\mu v} P_{\omega}^{\mu v} \phi_{\mu}(\mathbf{r}) \phi_{v}(\mathbf{r})
$$

The last three components (Coulomb, Hartree-Fock exchange, and exchange-correlation) of the excitation energy density in Eq. 22 on the other hand, all include both one-electron contributions (associated with difference density matrix) and two-electron contributions (associated with transition density matrix). Amongst, the Coulomb $(J)$ and Hartree-Fock exchange $(K)$ components can be evaluated as,

$$
\begin{aligned}
& \rho^{J}(\mathbf{r})=\sum_{\mu v, \lambda \sigma} \phi_{\mu}(\mathbf{r}) \phi_{v}(\mathbf{r}) V_{\lambda \sigma}(\mathbf{r})\left(P_{\omega}^{\mu v} P^{\lambda \sigma}+R_{\omega}^{\mu v} R_{\omega}^{\lambda \sigma}\right) \\
& \rho^{K}(\mathbf{r})=-\alpha_{K} \sum_{\mu v, \lambda \sigma} \phi_{\mu}(\mathbf{r}) \phi_{\lambda}(\mathbf{r}) V_{v \sigma}(\mathbf{r})\left(P_{\omega}^{\mu v} P^{\lambda \sigma}+R_{\omega}^{\mu v} R_{\omega}^{\lambda \sigma}\right)
\end{aligned}
$$

The computation of $\rho^{J}(\mathbf{r})$ and $\rho^{K}(\mathbf{r})$ can follow a similar procedure as that of ground-state energy components shown in Eqs. 15 and 16, but it will involve more matrix multiplications. A subtle but important issue here is that the two-electron contribution to $\rho^{K}(\mathbf{r})$ in Eq. 27. is not uniquely defined. This can be easily understood within the MO representation, where this excitation energy density component becomes

$$
\begin{aligned}
& \rho_{2}^{K}(\mathbf{r})=-\alpha_{K} \sum_{\mu v, \lambda \sigma} \phi_{\mu}(\mathbf{r}) \phi_{\lambda}(\mathbf{r}) V_{v \sigma}(\mathbf{r}) R_{\omega}^{\mu v} R_{\omega}^{\lambda \sigma} \\
& =-\alpha_{K} \sum_{i a, j b}\left[\psi_{a}(\mathbf{r}) \psi_{b}(\mathbf{r}) V_{i j}(\mathbf{r}) X_{a i} X_{b j}+\psi_{a}(\mathbf{r}) \psi_{j}(\mathbf{r}) V_{b i}(\mathbf{r}) X_{a i} Y_{b j}\right. \\
& \left.\quad+\psi_{b}(\mathbf{r}) \psi_{i}(\mathbf{r}) V_{a j}(\mathbf{r}) Y_{a i} X_{b j}+\psi_{i}(\mathbf{r}) \psi_{j}(\mathbf{r}) V_{a b}(\mathbf{r}) Y_{a i} Y_{b j}\right]
\end{aligned}
$$

and the first term (associated with $\mathbf{X} \otimes \mathbf{X}$ ) would dominate. For charge-transfer excitations, this density would be concentrated mainly on the electron acceptor, where virtual orbitals $a$ and $b$ reside. On the other hand, an equivalent way for distributing the two-electron Hartree-Fock exchange energy (that integrates to the same total exchange energy contribution to the excitation energy) is to transpose both (nonsymmetric) transition density matrices in 
Eq. 27

$$
\begin{aligned}
& \rho_{2}^{K}(\mathbf{r})=-\alpha_{K} \sum_{\mu v, \lambda \sigma} \phi_{\mu}(\mathbf{r}) \phi_{\lambda}(\mathbf{r}) V_{v \sigma}(\mathbf{r}) R_{\omega}^{v \mu} R_{\omega}^{\sigma \lambda} \\
& =-\alpha_{K} \sum_{i a, j b}\left[\psi_{i}(\mathbf{r}) \psi_{j}(\mathbf{r}) V_{a b}(\mathbf{r}) X_{a i} X_{b j}+\psi_{b}(\mathbf{r}) \psi_{i}(\mathbf{r}) V_{a j}(\mathbf{r}) X_{a i} Y_{a i}\right. \\
& \left.\quad+\psi_{a}(\mathbf{r}) \psi_{j}(\mathbf{r}) V_{b i}(\mathbf{r}) Y_{a i} X_{a i}+\psi_{a}(\mathbf{r}) \psi_{b}(\mathbf{r}) V_{i j}(\mathbf{r}) Y_{a i} Y_{b j}\right]
\end{aligned}
$$

For charge-transfer excitations, this produces an energy density mostly on the donor moiety, where occupied orbitals $i$ and $j$ are located. In this work, we will use the average between these two distributions (Eqs 28 and 29). For charge-transfer excitations, this means that the two-electron Hartree-Fock exchange energy (i.e. the electrostatic interaction between the particle and the hole) is evenly split between the donor and acceptor moieties.

Finally, the one-electron and two-electron contributions to the exchange-correlation term in Eq. 22 are

$$
\begin{aligned}
& \rho_{1}^{X C}(\mathbf{r})=\sum_{\mu \nu}\left(\sum_{\xi} \frac{\partial f_{\mathrm{xc}}}{\partial \xi} \frac{\partial \xi}{\partial P^{\mu \nu}}\right) P_{\omega}^{\mu \nu} \\
& \rho_{2}^{X C}(\mathbf{r})=\sum_{\mu v, \lambda \sigma} R_{\omega}^{\mu v}\left(\sum_{\xi, \xi^{\prime}} \frac{\partial^{2} f_{\mathrm{xc}}}{\partial \xi \partial \xi^{\prime}} \frac{\partial \xi}{\partial P^{\mu v}} \frac{\partial \xi^{\prime}}{\partial P^{\lambda \sigma}}\right) R_{\omega}^{\lambda \sigma}
\end{aligned}
$$

\subsection{Real-Space Partitioning Schemes}

Two sets of weights for real-space grid points - Becke weights ${ }^{23}$ and those from Fragment-Based Hirshfeld (FBH) analysis 27 - will be employed to partition the charge and energy densities onto different fragments.

Within the Becke scheme, which is widely employed for integrating the exchange-correlation contributions to the KS-DFT energy and Fock matrix, Lebedev quadrature points are added around each atom. The weight of each grid point is defined as

$$
w_{n}(\mathbf{r})=\frac{P_{n}(\mathbf{r})}{\sum_{m \in \text { atoms }} P_{m}(\mathbf{r})}
$$

with $P_{m}(\mathbf{r})$ being polynomial functions of the distance between the grid point from the $m$-th nucleus. For each molecular fragment (A), the collective weight is

$$
w_{A}^{\text {Becke }}(\mathbf{r})=\sum_{n \in A} w_{n}(\mathbf{r})
$$

Within the FBH analysis, one first computes the electron densities for isolated fragments, $\rho_{B}^{\text {isolated }}(\mathbf{r})$. The "promolecule" density for a molecular complex is defined as a sum of these fragment densities,

$$
\rho^{\text {promolecule }}(\mathbf{r})=\sum_{B} \rho_{B}^{\text {isolated }}(\mathbf{r})
$$

For each real-space grid point, a weight, $w_{A}(\mathbf{r})$, can be assigned to each fragment

$$
w_{A}^{\mathrm{FBH}}(\mathbf{r})=\frac{\rho_{A}^{\text {isolated }}(\mathbf{r})}{\rho^{\text {promolecule }}(\mathbf{r})}
$$

Note that FBH population was used previously to construct constrained density functional theory (CDFT) states of molecular complexes. 2775176

Using either set of atomic weights, we can partition the difference electron density in Eq. 25 and the excitation energy density in Eq. 22 onto different fragments,

$$
\begin{aligned}
(\Delta Q)_{A} & =\int w_{A}(\mathbf{r}) \rho_{\mathrm{diff}}(\mathbf{r}) d \mathbf{r} \\
\omega_{A} & =\int w_{A}(\mathbf{r}) \rho^{\omega}(\mathbf{r}) d \mathbf{r}
\end{aligned}
$$

In this work, the fragment charge in Eq. 36 was computed using the relaxed difference densities.

\subsection{Characterization of Electronic Excitations}

In our work, besides fragment charges, two other metrics will be used to distinguish charge-transfer excitations from local excitations. The first one is the widely-used $\Lambda$ factor proposed by Peach et al. ${ }^{[58]}$ For a given LR-TDDFT excited state, it will be computed as

$$
\Lambda=\frac{\sum_{a, i} \mathrm{O}_{a i}\left|X_{a i}+Y_{a i}\right|^{2}}{\sum_{a, i}\left|X_{a i}+Y_{a i}\right|^{2}}
$$

where $\mathrm{O}_{a i}$ is the overlap of the moduli of the $a$-th virtual orbital and the $i$-th occupied orbital,

$$
\mathrm{O}_{a i}=\int\left|\psi_{a}(\mathbf{r})\right|\left|\psi_{i}(\mathbf{r})\right| d \mathbf{r} .
$$

Alternatively, one can utilize the detachment ("hole") and attachment ("particle") densities, which can be computed by plugging the corresponding unrelaxed difference density matrix components in Eq 17 into Eq25. In a recent work, the overlap of detachment (or attachment) densities from separate LR-TDDFT calculations was employed to compare excited states computed using different basis sets. ${ }^{77}$ In this work, the overlap between the attachment and detachment densities of each excited state proposed first by Etienne ${ }^{50151}$

$$
S_{\mathrm{DA}}=\int\left[\rho^{\operatorname{detach}}(\mathbf{r})\right]^{\frac{1}{2}}\left[\rho^{\mathrm{attach}}(\mathbf{r})\right]^{\frac{1}{2}} d \mathbf{r}
$$

will be used as an alternative metric for assessing its character.

For each excited state, both criteria will fall in the range of $[0,1)$, with a smaller value indicating a stronger charge-transfer character.

\section{Computational Details}

Two model complexes were used to demonstrate the distribution of the excitation energy densities. The first was the ethylenetetrafluoroethylene $\left(\mathrm{C}_{2} \mathrm{H}_{4}-\mathrm{C}_{2} \mathrm{~F}_{4}\right)$ complex, which was widely used in the development of the range-separated functionals. ${ }^{7879}$ Both $\mathrm{C}_{2} \mathrm{H}_{4}$ and $\mathrm{C}_{2} \mathrm{~F}_{4}$ were optimized using the $\omega \mathrm{B} 97 \mathrm{X}$-D functional ${ }^{80}$ and $6-311++G(d, p)$ basis set. ${ }^{81}$ Then, these monomers were combined together (without further geometry relaxation) into three different configurations:

- Cofacial (labeled as F, Figure 11). Two monomers were stacked on top of each other with a $5 \AA$ distance in between. 
Table 1 Excitation character metrics $\left(\Lambda\right.$ and $\left.S_{\mathrm{DA}}\right)$, FBH fragment charges $\left(\Delta Q_{A}\right)$, FBH fragment excitation energies $\left(\omega_{A}\right)$ for the lowest local excitation and charge-transfer excitations of three $\mathrm{C}_{2} \mathrm{H}_{4}-\mathrm{C}_{2} \mathrm{~F}_{4}$ configurations. Obtained from LR-TDDFT calculations using the PBE0 functional and 6-31G(d) basis set.

\begin{tabular}{|c|c|c|c|c|c|c|c|c|}
\hline \multirow{2}{*}{ Configuration } & \multirow{2}{*}{ ES\# } & \multirow{2}{*}{$\Lambda$} & \multirow{2}{*}{$S_{\mathrm{DA}}$} & \multicolumn{2}{|c|}{$Q_{A}$ (a.u.) } & \multicolumn{3}{|c|}{$\omega_{A}$ or $\omega(\mathrm{eV})$} \\
\hline & & & & $\mathrm{C}_{2} \mathrm{H}_{4}$ & $\mathrm{C}_{2} \mathrm{~F}_{4}$ & $\mathrm{C}_{2} \mathrm{H}_{4}$ & $\mathrm{C}_{2} \mathrm{~F}_{4}$ & Total \\
\hline $\bar{F}$ & 2 & 0.623 & 0.631 & 0.000 & 0.000 & -0.003 & 7.129 & 7.125 \\
\hline P1 & 1 & 0.611 & 0.628 & -0.010 & 0.010 & 0.026 & 7.074 & 7.099 \\
\hline P2 & 1 & 0.623 & 0.631 & -0.001 & 0.001 & 0.005 & 7.121 & 7.126 \\
\hline P1 & 2 & 0.015 & 0.006 & -0.990 & 0.990 & 0.426 & 6.819 & 7.244 \\
\hline P2 & 2 & 0.005 & 0.003 & -0.999 & 0.999 & 0.466 & 6.835 & 7.301 \\
\hline
\end{tabular}

- Planar 1 (labeled as P1, Figure 2). Two monomers laid sideby-side with a $5 \AA$ Aistance between the closest carbon atoms.

- Planar 2 (labeled as P2, Figure 3). Two monomers laid endto-end with a $5 \AA$ distance between the closest carbon atoms.

The second was the oxyluciferin molecule (OLH or $\left.\mathrm{OxyLH}_{2}\right)$, where 6'-oxygen is protonated, in complex with a water molecule. Its anionic form has been shown to be the light emitter in firefly bioluminescence. ${ }^{82}$ Three different types of configurations would also be studied:

- Hydrogen-bonded 1 and 2 (labelled as HB1 and HB2, Figure 5). Water molecule formed a hydrogen bond with the 5'oxygen or 6'-oxygen of OLH. Both complexes were optimized at $\omega \mathrm{B} 97 \mathrm{X}-\mathrm{D} / 6-311++\mathrm{G}(\mathrm{d}, \mathrm{p})$ level of theory.

- T-shape (labelled as T, Figure 6). Water molecule formed a T-shape complex with OLH, with its one $\mathrm{O}-\mathrm{H}$ bond pointing towards the center of the benzene ring of OLH. A series of geometries were obtained via restrained geometry optimization with varying distances $(1.6,1.7,1.8,1.9,2.0$, and 2.1 $\AA$ ) between the water hydrogen atom and the center of the OLH benzene ring.

The evaluation and partitioning of excitation energy densities were implemented within a development version of the PYSCF software package. ${ }^{83}$ Standard and restrained geometry optimization and LR-TDDFT/TIP3P excitation energy calculations of different $\mathrm{OLH}-\mathrm{H}_{2} \mathrm{O}$ configurations were carried out by the Q-CHEM software package. ${ }^{84}$ All geometries used in this article, together with their $\omega \mathrm{B} 97 \mathrm{X}-\mathrm{D} / 6-311++\mathrm{G}(\mathrm{d}, \mathrm{p})$ energies as computed by Q-CHEM, are provided in the Electronic Supplementary Information.

\section{Results}

\subsection{Ground-State Energy Density}

Before proceeding to present our results on the excitation energy density of the two molecular complexes, it would be beneficial to analyze and understand the ground-state energy densities. This has already been carried out in the accompanying paper, where the ground-state energy densities of $\mathrm{N}_{2}$ molecule and a small $\mathrm{Ag}_{4}$ cluster were analyzed. Here is a summary of our key understandings of the ground-state energy densities:
- The kinetic energy density $\left(\rho_{0}^{T}\right)$ and the Coulomb energy density $\left(\rho_{0}^{J}\right)$ are always positive. In contrast, the nuclear attraction energy density $\left(\rho_{0}^{N}\right)$, Hartree-Fock exchange energy density $\left(\rho_{0}^{K}\right)$, and exchange-correlation energy density $\left(\rho_{0}^{X C}\right)$ are all negative. $\rho_{0}^{K}$ and $\rho_{0}^{X C}$ are substantially smaller in the magnitude than other energy densities.

- The total ground-state energy density $\left(\rho_{0}^{E}\right)$ is usually negative, and thus has an opposite sign as the charge density. But $\rho_{0}^{E}$ has a positive value in a "donut" region around each nucleus, due to a slower decay of the kinetic energy density there.

- All energy density components decay rapidly away from the molecule.

\subsection{Ethylene-Tetrafluoroethylene $\left(\mathrm{C}_{2} \mathrm{H}_{4}-\mathrm{C}_{2} \mathrm{~F}_{4}\right)$ Complexes}

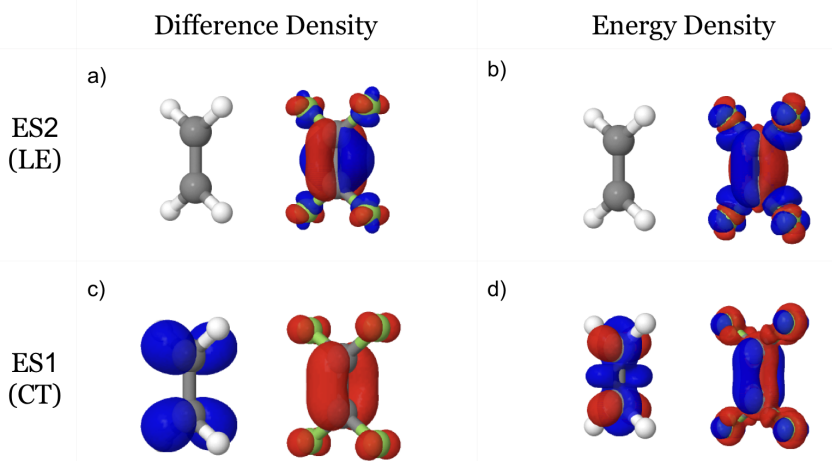

Fig. 1 Difference density and excitation energy density plots (isovalue $=0.01 \mathrm{au}$; red $=$ negative) for the lowest $(\mathrm{a}, \mathrm{b})$ local excitation and $(\mathrm{c}, \mathrm{d})$ charge transfer excitation of the $\mathbf{F}$ (stacked) configuration of the $\mathrm{C}_{2} \mathrm{H}_{4}$ $\mathrm{C}_{2} \mathrm{~F}_{4}$ complex from LR-TDDFT calculations with PBE0 functional and 6-31G(d) basis set.

Ethylene-tetrafluoroethylene is an interesting system. With the HOMO of the complex coming from $\mathrm{C}_{2} \mathrm{~F}_{4}$ and the LUMO from $\mathrm{C}_{2} \mathrm{H}_{4}$, one of the low-lying excited states involves a charge transfer between these orbitals from different fragments. Such a chargetransfer state can have lower energy than local excitations on either $\mathrm{C}_{2} \mathrm{~F}_{4}$ or $\mathrm{C}_{2} \mathrm{H}_{4}$ fragment, especially with the use of conventional hybrid density functionals and smaller basis sets. 
Table 1 collects information on the lowest two excitations for each of the three $\mathrm{C}_{2} \mathrm{H}_{4}-\mathrm{C}_{2} \mathrm{~F}_{4}$ configurations, which were obtained from LR-TDDFT calculations using the PBE0 functional ${ }^{85}$ and 6$31 \mathrm{G}(\mathrm{d})$ basis set. ${ }^{8687}$ The corresponding difference densities and excitation energy densities are shown in Figures 1, 2, and 3.

The charge-transfer character of each excited state can be first assessed by examining the FBH fragment charges as defined in Eq. 36. For the cofacial configuration (F), our LR-TDDFT/PBE0/6$31 \mathrm{G}(\mathrm{d})$ calculation predicted a charge-transfer excited state (with $0.997 e^{-}$within the $\mathrm{FBH}$ scheme shifted from $\mathrm{C}_{2} \mathrm{~F}_{4}$ to $\mathrm{C}_{2} \mathrm{H}_{4}$; see Figure 1 for the density change) to be lower than a local excitation on $\mathrm{C}_{2} \mathrm{~F}_{4}$ (with $0.000 e^{-}$shifted; Figure $1 \mathrm{1}$ ). On the other hand, for two other configurations (P1 and P2), the charge-transfer state (with 0.990 or $0.999 e^{-}$; Figures 2k and 3c) has a higher energy than the corresponding local excitations. Similar amounts of charge transfer between the fragments can be found in Table S10 for the Becke and ESP-derived charge schemes.

Difference Density

a)

ES1

(LE)

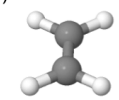

c)

ES2

(CT)

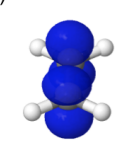

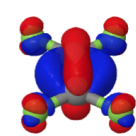

b)

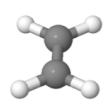

d)
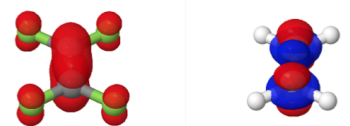

Energy Density

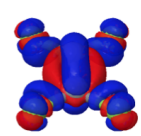

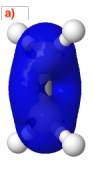

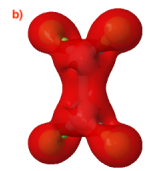

Fig. 4 Kinetic energy density (isovalue $=0.01 \mathrm{au}$ ) for a) $\mathrm{C}_{2} \mathrm{H}_{4} \mathrm{LUMO}$ and b) $\mathrm{C}_{2} \mathrm{~F}_{4} \mathrm{HOMO}$. The latter was multiplied by -1 to be consistent with its contribution to the kinetic energy density of the charge-transfer excitation.

for localized excitations, and distributed over both fragments for charge-transfer excitations. We can easily recognize two distinct contributions to each excitation energy density:

- "normal" contribution, which has the opposite sign (color) as the difference density. This is similar to our observation for the ground state energy density as summarized above in Section 4.1. For the lowest charge-transfer excitation of the cofacial configuration, for example, an electron was detached from $\mathrm{C}_{2} \mathrm{~F}_{4} \mathrm{HOMO}$ (see the red "cloud" in Figure 1 $\mathrm{k}$ ). Accordingly, one can recognize a negative electron density of a similar shape on $\mathrm{C}_{2} \mathrm{~F}_{4}$ in Figure $1 \mathrm{~d}$.

- kinetic energy contribution, which has the same sign (color) as the different density but has a very different shape. For the cofacial configuration, the kinetic energy densities are shown in Fig 4 for $\mathrm{C}_{2} \mathrm{H}_{4}$ LUMO and $\mathrm{C}_{2} \mathrm{~F}_{4}$ HOMO, which combine together to yield the kinetic energy density of the lowest charge-transfer excitation. Such a contribution is clearly responsible for the extra features within and near the molecular planes in the excitation energy density plots in, for instance, Figure $1 \mathrm{~d}$.

When the excitation energy densities are integrated over each fragment according to Eq. 37, the total excitation energy is divided into fragment contributions. In accordance with our expectation, the excitation energy was shown in Tables 1 and S10 to concentrate on one fragment $\left(\mathrm{C}_{2} \mathrm{~F}_{4}\right.$ in tested cases) for local excitations. For charge-transfer excitations, significant $(>0.3 \mathrm{eV})$ and positive excitation energy values were observed on both donor and acceptor fragments. However, the value on the donor fragment $\left(\mathrm{C}_{2} \mathrm{~F}_{4}\right.$ in these cases) are substantially larger, reflecting that (the absolute value of) HOMO energy (i.e. ionization potential within Koopman's theorem) is usually larger than the LUMO energy (i.e. electron affinity within Koopman's theorem). For instance, the electron donors contributed 6.7-6.8 eV to the total excitation energies while only $0.3-0.5 \mathrm{eV}$ came from electron acceptors (see Table 1). As we mentioned in the introduction, the fragment excitation energies on the donor (acceptor) fragment can be regarded as effective energies of the "hole" ("particle") in the charge-transfer excitations.

\subsection{Oxyluciferin-Water Complexes}

The neutral oxyluciferin molecule (OLH) can form multiple hydrogen bond complexes with a single water molecule. As shown in Figure 5 both 5'-oxygen (on the thiazole ring) and 6'-oxygen (on the benzothiazole ring) could serve as the hydrogen bond acceptor leading to two complexes (HB1 and HB2). As indicated by the 
Table 2 Binding energies, excitation character metrics ( $\Lambda$ and $S_{\mathrm{DA}}$ ), FBH fragment charges, and FBH fragment excitation energies for $\mathrm{HOMO} \rightarrow \mathrm{LUMO}$ excitations of three neutral $\mathrm{OLH}-\mathrm{H}_{2} \mathrm{O}$ configurations. Obtained from LR-TDDFT calculations with the PBE0 functional and 6-31G(d) basis set.

\begin{tabular}{|c|c|c|c|c|c|c|c|c|c|c|}
\hline \multirow{2}{*}{ Con } & \multicolumn{2}{|c|}{$\Delta \mathrm{E}_{\text {bind }}(\mathrm{kcal} / \mathrm{mol})$} & \multirow{2}{*}{ ES\# } & \multirow{2}{*}{$\Lambda$} & \multirow{2}{*}{$S_{\mathrm{DA}}$} & \multicolumn{2}{|c|}{$\Delta Q_{A}(\mathrm{au})$} & \multicolumn{3}{|c|}{$\omega_{A}$ or $\omega(\mathrm{eV})$} \\
\hline & w/o BSSE & w/ BSSE & & & & OLH & $\mathrm{H}_{2} \mathrm{O}$ & OLH & $\mathrm{H}_{2} \mathrm{O}$ & Total \\
\hline HB1 & -8.798 & -6.599 & 1 & 0.627 & 0.632 & 0.006 & -0.006 & 3.495 & 0.020 & 3.515 \\
\hline HB2 & -6.115 & -4.092 & 2 & 0.640 & 0.632 & -0.006 & 0.006 & 3.638 & -0.010 & 3.628 \\
\hline T1.6 & 7.224 & 7.888 & 1 & 0.594 & 0.607 & -0.150 & 0.150 & 2.396 & 1.108 & 3.504 \\
\hline T1.7 & 4.192 & 7.554 & 1 & 0.602 & 0.616 & -0.118 & 0.118 & 2.719 & 0.828 & 3.547 \\
\hline T1.8 & 1.954 & 4.910 & 1 & 0.602 & 0.636 & -0.087 & 0.087 & 2.994 & 0.582 & 3.576 \\
\hline T1.9 & 0.380 & 2.934 & 2 & 0.615 & 0.631 & -0.067 & 0.067 & 3.175 & 0.420 & 3.595 \\
\hline T2.0 & -0.660 & 1.550 & 2 & 0.622 & 0.629 & -0.052 & 0.052 & 3.305 & 0.303 & 3.608 \\
\hline T2.1 & -1.361 & 0.502 & 2 & 0.625 & 0.630 & -0.037 & 0.037 & 3.412 & 0.197 & 3.609 \\
\hline
\end{tabular}

BSSE-corrected binding energies in Table 2, these hydrogen bonds could stabilize the complex by 4 to $6.5 \mathrm{kcal} / \mathrm{mol}$.

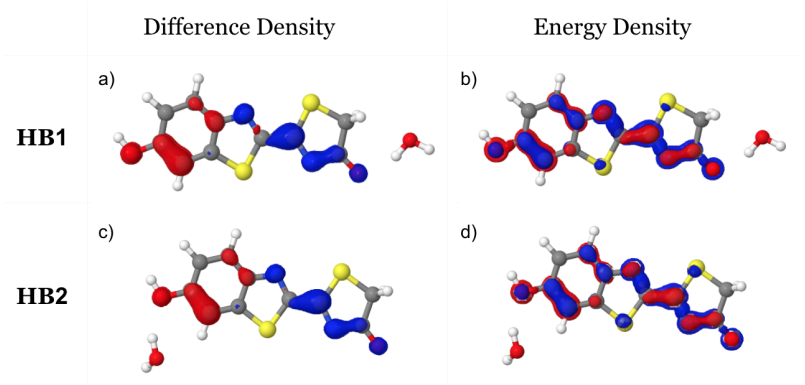

Fig. 5 Difference density and excitation energy density plots (isovalue $=0.005 \mathrm{au}$; red $=$ negative) for the $\mathrm{HOMO} \rightarrow$ LUMO excitations of two hydrogen-bonded $\mathrm{OLH}-\mathrm{H}_{2} \mathrm{O}$ complexes. Obtained from LR-TDDFT calculations with PBE0 functional and 6-31G(d) basis set.

The HOMO $\rightarrow$ LUMO vertical excitation of oxyluciferin involves a partial charge transfer from the benzothiazole ring to the thiazole ring. As shown in the difference density plots in Figure $5 \mathrm{a}$ and 5 , such a partial charge transfer was largely unchanged upon the binding of a water molecule in the two hydrogen bond complexes. In Table 2, the fragment charges on OLH or water in HB1 and HB2 were found to be only $0.006 e^{-}$. Accordingly, the excitation energy densities in Figure $5 \mathrm{p}$ and $5 \mathrm{~d}$ remained localized on OLH, with the fragment excitation energies integrated to only $0.02 \mathrm{eV}$ (HB1) and $-0.01 \mathrm{eV}$ (HB2) on $\mathrm{H}_{2} \mathrm{O}$ molecule in Table 2 .

However, the picture can be quite different when oxyluciferin formed a T-shape complex (T) with a water molecule. As shown in the left column of Figure 6, the detachment density could more easily "spill" over to the water molecule, which corresponds to a "spillover" of OLH HOMO to the water molecule. For the HOMO $\rightarrow$ LUMO excitation of these T-shape complexes, Table 2 thus showed a net loss of 0.037 to $0.150 e^{-}$from the water molecule. This was accompanied by a "spillover" of the excitation energy density to the water molecule in each of these T-shape complexes (see the right column of Figure 6), with the fragment excitation energy on water computed to be 0.197 to $1.108 \mathrm{eV}$.
Difference Density

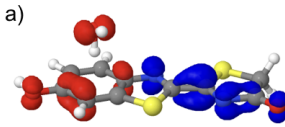

c)

T1.7

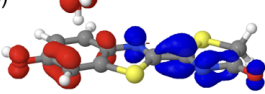

e)

$\mathbf{T} 1.8$

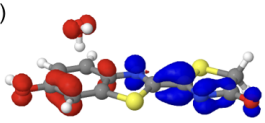

g)

T1.9
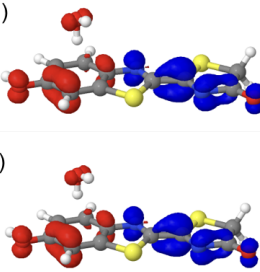

T2.1

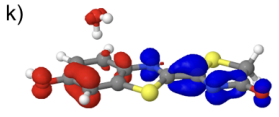

Energy Density

b)

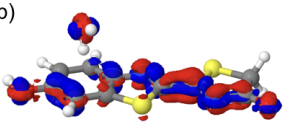

d)

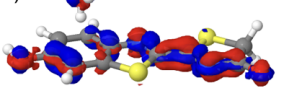

f)

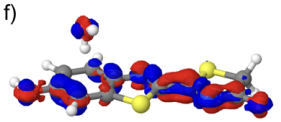

h)
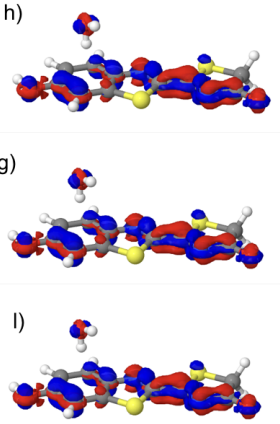

Fig. 6 Difference density and excitation energy density plots (isovalue surface of 0.005 au; red $=$ negative) for the HOMO $\rightarrow$ LUMO excitations of six T-shape $\mathrm{OLH}-\mathrm{H}_{2} \mathrm{O}$ complexes (with the distance between water hydrogen and OLH benzene ring center ranging from 1.6 to $2.1 \AA$ ). Obtained from LR-TDDFT calculations with PBE0 functional and 6-31G(d) basis set.

\section{Discussions}

Functional and Basis Set. So far, we have focused our report on LR-TDDFT calculations using the PBE0 functional and 6-31G(d) basis set. Such a choice was made on two practical considerations - the easiness of identifying the charge-transfer excited state and a moderate computational cost. But, As shown in Tables S1-S9, our energy density analysis is also fully functioning with larger basis sets.

Our implementation of excitation energy densities is also applicable to other functionals, such as pure and range-separated 
functionals, which require the use of appropriate electron repulsion operators, if any, in the calculation of exchange energy density components. Results with the $\mathrm{PBE}^{88}$ and $\omega \mathrm{B} 97 \mathrm{X}-\mathrm{D}$ functionals are shown in Tables S1, S3, S4, S6, S7, and S9 for $\mathrm{C}_{2} \mathrm{H}_{4}-\mathrm{C}_{2} \mathrm{~F}_{4}$ dimers. For local excitations, the excitation energy remain localized with these two functionals. On the other hand, in a charge-transfer excitation, the acceptor portion of the excitation energy (which can be interpreted as the effective energy of the "particle") arises from a cancellation of the kinetic energy of the "particle" and other contributions. While it is consistently positive with the $\omega$ B97X-D functional, it can acquire a negative value with PBE and PBE0 functionals, likely due to lower (and sometimes even negative) LUMO energy values.

Computational Cost. Within our preliminary implementation, the computational cost for obtaining excitation energy density arises mainly from the evaluation of $V_{\lambda \sigma}$, which is the grid-based electrostatic potential of each function pair (i.e. pairs of atomic basis functions) in Eq. 14. $V_{\lambda \sigma}$ is needed in the construction of Coulomb and exchange energy densities in Eqs. 26 and 27. Such a calculation would become rather prohibitive for large systems and/or larger basis sets. We note that the resolution-of-the-identity (RI) approach 89 was employed to approximate the ground-state Hartree-Fock exchange energy density, ${ }^{9798}$ and thus anticipate a similar use of the RI approach to accelerate the evaluation of excitation energy densities.

Table 3 TDDFT (for the full system), TDDFT/TIP3P excitation energies, and the differences between them (in eV) for the HOMO $\rightarrow$ LUMO excitations of the $\mathrm{HB} 1, \mathrm{HB} 2$, and T-shape configurations of neutral $\mathrm{OLH}-\mathrm{H}_{2} \mathrm{O}$ calculated with the PBE0 functional and 6-31G(d) basis set by Q-CHEM.

\begin{tabular}{lcccr}
\hline Configuration & ES\# & $\omega_{\text {Full-TDDFT }}$ & $\omega_{\text {TDDFT/TIP3P }}$ & \multicolumn{1}{c}{$\Delta \omega$} \\
\hline HB1 & 1 & 3.516 & 3.545 & 0.039 \\
HB2 & 2 & 3.630 & 3.620 & -0.010 \\
T1.6 & 1 & 3.507 & 3.663 & 0.156 \\
T1.7 & 1 & 3.550 & 3.663 & 0.113 \\
T1.8 & 1 & 3.578 & 3.661 & 0.073 \\
T1.9 & 2 & 3.597 & 3.656 & 0.059 \\
T2.0 & 2 & 3.610 & 3.654 & 0.044 \\
T2.1 & 2 & 3.611 & 3.642 & 0.031 \\
\hline
\end{tabular}

Fluorophore-Solvent Charge Transfer. For the T-shape oxyluciferin-water complexes, we have noticed a "spillover" of detachment/attachment density and excitation energy density to the water molecule. This is ultimately due to a strong interaction between the fluorophore and water frontier orbitals, which can only be captured by coupling orbitals from different fragments. 99 As shown in Table 3, this has led the LR-TDDFT/TIP3P model to systematically overestimate the vertical excitation energies of T-shape complexes.

An individual T-shape complex can be energetically unfavorable, as evident by the binding energies in Table 2. In TDDFT/TIP3P molecular dynamics simulation of the solvated OLH (and several other fluorophores), we have nevertheless observed multiple water molecules (in the first solvation shell) forming T-shape complexes with the fluorophore. Lacking a treatment of charge-transfer interactions between the QM and MM regions, LR-TDDFT/TIP3P can systematically overestimate the vertical excitation energy of the fluorophore (within in first solvation shell) by as much as 0.10-0.15 eV. For a more accurate description of solvatochromic effect (especially with multiple solvents), it is therefore desirable to extend orbital-dependent inter-fragment charge-transfer models (such as the EFP model) 100 to excited state calculations.

\section{Conclusions}

In this article, we presented a method for distributing the LRTDDFT excitation energy over the real space, and thus for acquiring the grid-based excitation energy density for each excited state. Due to the kinetic energy density term, the excitation energy distribution was found to be slightly more complicated than the difference electron density (between the ground and excited states).

For locally-excited states (as indicated by the attachment/detachment densities and changes in fragment charges), the excitation energy density was concentrated on a single molecular fragment, just as expected. In charge-transfer excitations, such as the ones in the $\mathrm{C}_{2} \mathrm{H}_{4}-\mathrm{C}_{2} \mathrm{~F}_{4}$ complex, the excitation energy density would be distributed over both donor and acceptor fragments, with a higher percentage of the excitation energy allocated on the donor fragment. Fragment excitation energies from a chargetransfer excitation can be regarded as the effective energies for the "hole" and "particle", respectively.

For excitations with a partial charge transfer between a fluorophore and water, such as T-shape OLH-water complexes, a small percentage of the excitation energy was found on the water molecules. The challenge to model such an effect with QM/MMtype methods stems from inter-fragment orbital mixing and might motivate the development of new methodologies to capture solutesolvent charge-transfer effects on electronic transitions.

\section{Conflicts of interest}

There are no conflicts to declare.

\section{Acknowledgements}

YS thanks Drs. John Herbert, Aurelian de la Lande, Xiaosong Li, and Weitao Yang for helpful discussions. YS is supported by the National Institutes of Health (grant: R01GM135392), Oklahoma Center for the Advancement of Science and Technology (grant: HR18-130), and the Office of the Vice President of Research and the College of Art and Sciences at the University of Oklahoma (OU). WL acknowledges financial support from the National Natural Science Foundation of China (Grant Nos. 21573177 and 21833006). BW acknowledges funding from the US Department of Energy (Grant No. DE-SC0020300). CMA is supported by the Department of Energy under grant DE-SC0012273. The computing for this project was performed at the OU Supercomputing Center for Education \& Research (OSCER) and the Center of Functional Nanomaterials (CFN). CFN is a U.S. DOE Office of Science Facility, at the Brookhaven National Laboratory under Contract No. DE-SC0012704. 


\section{References}

1 J. W. Storer, D. J. Giesen, C. J. Cramer and D. G. Truhlar, Class IV Charge Models: A New Semiempirical Approach in Quantum Chemistry, J. Comput. Aid. Mol. Des., 1995, 9, 87-110.

2 A. M. Pendas, M. A. Blanco and E. Francisco, Chemical Fragments in Real Space: Definitions, Properties, and Energetic Decompositions, J. Comput. Chem., 2007, 28, 161-184.

3 Y. Mei, A. C. Simmonett, F. C. Pickard, R. A. DiStasio, B. R. Brooks and Y. Shao, Numerical Study on the Partitioning of the Molecular Polarizability into Fluctuating Charge and Induced Atomic Dipole Contributions, J. Phys. Chem. A, 2015, 119, 5865-5882.

4 R. S. Mulliken, Electronic Population Analysis on LCAO-MO Molecular Wave Functions. I, J. Chem. Phys., 1955, 23, 18331840.

5 P.-O. Löwdin, On the Non-Orthogonality Problem Connected with the Use of Atomic Wave Functions in the Theory of Molecules and Crystals, J. Chem. Phys., 1950, 18, 365-375.

6 J. Baker, Classical Chemical Concepts from ab initio SCF Calculations, Theor. Chim. Acta, 1985, 68, 221-229.

7 R. F. W. Bader and P. M. Beddall, Virial Field Relationship for Molecular Charge Distributions and the Spatial Partitioning of Molecular Properties, J. Chem. Phys., 1972, 56, 3320-3329.

8 R. F. W. Bader, Atoms in Molecules: A Quantum Theory, Clarendon Press ; Oxford University Press, Oxford [England] : New York, 1994.

9 R. F. W. Bader and C. F. Matta, Atomic Charges Are Measurable Quantum Expectation Values: A Rebuttal of Criticisms of QTAIM Charges, J. Phys. Chem. A, 2004, 108, 8385-8394.

10 J. P. Foster and F. Weinhold, Natural hybrid orbitals, J. Am. Chem. Soc., 1980, 102, 7211-7218.

11 A. E. Reed, R. B. Weinstock and F. Weinhold, Natural Population Analysis, J. Chem. Phys., 1985, 83, 735-746.

12 E. D. Glendening, C. R. Landis and F. Weinhold, Natural Bond Orbital Methods, WIREs Comput. Mol. Sci., 2012, 2, 1-42.

13 U. C. Singh and P. A. Kollman, An approach to computing electrostatic charges for molecules, J. Comput. Chem., 1984, 5, 129-145.

14 L. E. Chirlian and M. M. Francl, Atomic Charges Derived from Electrostatic Potentials: A Detailed Study, J. Comput. Chem., 1987, 8, 894-905.

15 C. M. Breneman and K. B. Wiberg, Determining AtomCentered Monopoles from Molecular Electrostatic Potentials. The Need for High Sampling Density in Formamide Conformational Analysis, J. Comput. Chem., 1990, 11, 361-373.

16 B. H. Besler, K. M. Merz and P. A. Kollman, Atomic Charges Derived from Semiempirical Methods, J. Comput. Chem., 1990, 11, 431-439.

17 C. I. Bayly, P. Cieplak, W. Cornell and P. A. Kollman, A wellbehaved electrostatic potential based method using charge restraints for deriving atomic charges: the RESP model, $J$. Phys. Chem., 1993, 97, 10269-10280.

18 W. D. Cornell, P. Cieplak, C. I. Bayly and P. A. Kollman,
Application of RESP Charges to Calculate Conformational Energies, Hydrogen Bond Energies, and Free Energies of Solvation, J. Am. Chem. Soc., 1993, 115, 9620-9631.

19 M. M. Francl, C. Carey, L. E. Chirlian and D. M. Gange, Charges Fit to Electrostatic Potentials. II. Can Atomic Charges Be Unambiguously Fit to Electrostatic Potentials?, J. Comput. Chem., 1996, 17, 367-383.

20 A. Laio, J. VandeVondele and U. Rothlisberger, D-RESP: Dynamically Generated Electrostatic Potential Derived Charges from Quantum Mechanics/Molecular Mechanics Simulations, J. Phys. Chem. B, 2002, 106, 7300-7307.

$21 \mathrm{H}$. Hu, Z. Lu and W. Yang, Fitting Molecular Electrostatic Potentials from Quantum Mechanical Calculations, J. Chem. Theory Comput., 2007, 3, 1004-1013.

22 M. Schauperl, P. S. Nerenberg, H. Jang, L.-P. Wang, C. I. Bayly, D. L. Mobley and M. K. Gilson, Non-Bonded Force Field Model with Advanced Restrained Electrostatic Potential Charges (RESP2), Commun. Chem., 2020, 3, 44.

23 A. D. Becke, A multicenter numerical integration scheme for polyatomic molecules, J. Chem. Phys., 1988, 88, 2547-2553.

24 F. L. Hirshfeld, Bonded-atom fragments for describing molecular charge densities, Theor. Chim. Acta, 1977, 44, 129-138.

25 F. L. Hirshfeld, XVII. Spatial Partitioning of Charge Density, Israel J. Chem., 1977, 16, 198-201.

26 F. De Proft, C. Van Alsenoy, A. Peeters, W. Langenaeker and P. Geerlings, Atomic Charges, Dipole moments, and Fukui Functions Using the Hirshfeld Partitioning of the Electron Density, J. Comput. Chem., 2002, 23, 1198-1209.

27 J. Rezac and A. de la Lande, Robust, Basis-Set Independent Method for the Evaluation of Charge-Transfer Energy in Noncovalent Complexes, J. Chem. Theory Comput., 2015, 11, 528-537.

28 P. Bultinck, C. V. Alsenoy, P. W. Ayers and R. Carbó-Dorca, Critical analysis and extension of the Hirshfeld atoms in molecules, J. Chem. Phys., 2007, 126, 144111.

29 P. Bultinck, P. W. Ayers, S. Fias, K. Tiels and C. Van Alsenoy, Uniqueness and Basis Set Dependence of Iterative Hirshfeld Charges, Chem. Phys. Lett., 2007, 444, 205-208.

30 P. Bultinck, D. L. Cooper and D. Van Neck, Comparison of the Hirshfeld-I and Iterated Stockholder Atoms in Molecules Schemes, Phys. Chem. Chem. Phys., 2009, 11, 3424.

31 D. M. Elking, L. Perera and L. G. Pedersen, HPAM: Hirshfeld Partitioned Atomic Multipoles, Comput. Phys. Commun., 2012, 183, 390-397.

32 T. C. Lillestolen and R. J. Wheatley, Redefining the atom: atomic charge densities produced by an iterative stockholder approach, Chem. Commun., 2008, 5909.

33 T. Verstraelen, P. Ayers, V. Van Speybroeck and M. Waroquier, The Conformational Sensitivity of Iterative Stockholder Partitioning Schemes, Chem. Phys. Lett., 2012, 545, 138-143.

34 T. Verstraelen, P. W. Ayers, V. Van Speybroeck and M. Waroquier, Hirshfeld-E Partitioning: AIM Charges with an Improved Trade-off between Robustness and Accurate Electrostatics, J. Chem. Theory Comput., 2013, 9, 2221-2225. 
35 T. A. Manz and D. S. Sholl, Chemically Meaningful Atomic Charges That Reproduce the Electrostatic Potential in Periodic and Nonperiodic Materials, J. Chem. Theory Comput., 2010, 6, 2455-2468.

36 T. A. Manz and D. S. Sholl, Improved Atoms-in-Molecule Charge Partitioning Functional for Simultaneously Reproducing the Electrostatic Potential and Chemical States in Periodic and Nonperiodic Materials, J. Chem. Theory Comput., 2012, 8, 2844-2867.

37 T. A. Manz and N. G. Limas, Introducing DDEC6 Atomic Population Analysis: Part 1. Charge Partitioning Theory and Methodology, RSC Adv., 2016, 6, 47771-47801.

38 N. G. Limas and T. A. Manz, Introducing DDEC6 Atomic Population Analysis: Part 2. Computed Results for a Wide Range of Periodic and Nonperiodic Materials, RSC Adv., 2016, 6, 45727-45747.

39 T. A. Manz, Introducing DDEC6 Atomic Population Analysis: Part 3. Comprehensive Method to Compute Bond Orders, RSC Adv., 2017, 7, 45552-45581.

40 R. M. Olson, A. V. Marenich, C. J. Cramer and D. G. Truhlar, Charge Model 4 and Intramolecular Charge Polarization, $J$. Chem. Theory Comput., 2007, 3, 2046-2054.

41 A. V. Marenich, S. V. Jerome, C. J. Cramer and D. G. Truhlar, Charge Model 5: An Extension of Hirshfeld Population Analysis for the Accurate Description of Molecular Interactions in Gaseous and Condensed Phases, J. Chem. Theory Comput., 2012, 8, 527-541.

42 R. G. Parr and W. Yang, Density Functional Approach to the Frontier-Electron Theory of Chemical Reactivity, J. Am. Chem. Soc., 1984, 106, 4049-4050.

43 W. Yang, A. J. Cohen, F. De Proft and P. Geerlings, Analytical Evaluation of Fukui Functions and Real-Space Linear Response Function, J. Chem. Phys., 2012, 136, 144110.

44 F. Heidar-Zadeh, R. A. Miranda-Quintana, T. Verstraelen, P. Bultinck and P. W. Ayers, When is the Fukui Function Not Normalized? The Danger of Inconsistent Energy Interpolation Models in Density Functional Theory, J. Chem. Theory Comput., 2016, 12, 5777-5787.

45 F. Plasser, M. Wormit and A. Dreuw, New tools for the systematic analysis and visualization of electronic excitations. I. Formalism, J. Chem. Phys., 2014, 141, 024106.

46 F. Plasser, S. A. Bäppler, M. Wormit and A. Dreuw, New tools for the systematic analysis and visualization of electronic excitations. II. Applications, J. Chem. Phys., 2014, 141, 024107.

47 F. Plasser, TheoDORE: A toolbox for a Detailed and Automated Analysis of Electronic Excited State Computations, $J$. Chem. Phys., 2020, 152, 084108.

48 T. Le Bahers, C. Adamo and I. Ciofini, A Qualitative Index of Spatial Extent in Charge-Transfer Excitations, J. Chem. Theory Comput., 2011, 7, 2498-2506.

49 C. A. Guido, P. Cortona, B. Mennucci and C. Adamo, On the Metric of Charge Transfer Molecular Excitations: A Simple Chemical Descriptor, J. Chem. Theory Comput., 2013, 9, 31183126.

50 T. Etienne, X. Assfeld and A. Monari, Toward a Quantita- tive Assessment of Electronic Transitions' Charge-Transfer Character, J. Chem. Theory Comput., 2014, 10, 3896-3905.

51 T. Etienne, X. Assfeld and A. Monari, New Insight into the Topology of Excited States through Detachment/Attachment Density Matrices-Based Centroids of Charge, J. Chem. Theory Comput., 2014, 10, 3906-3914.

52 T. Etienne, Probing the Locality of Excited States with Linear Algebra, J. Chem. Theory Comput., 2015, 11, 1692-1699.

53 B. Moore, H. Sun, N. Govind, K. Kowalski and J. Autschbach, Charge-Transfer Versus Charge-Transfer-Like Excitations Revisited, J. Chem. Theory Comput., 2015, 11, 3305-3320.

54 G. Bistoni, L. Belpassi and F. Tarantelli, Advances in Charge Displacement Analysis, J. Chem. Theory Comput., 2016, 12, 1236-1244.

55 M. Savarese, C. A. Guido, E. Bremond, I. Ciofini and C. Adamo, Metrics for Molecular Electronic Excitations: A Comparison between Orbital- and Density-Based Descriptors, J. Phys. Chem. A, 2017, 121, 7543-7549.

56 M. Campetella, F. Maschietto, M. J. Frisch, G. Scalmani, I. Ciofini and C. Adamo, Charge Transfer Excitations in TDDFT: A Ghost-Hunter Index, J. Comput. Chem., 2017, 38, 2151-2156.

57 M. Alipour and S. Damiri, Development of a Novel Index for Analysis of Electronically Excited States, ChemPhysChem, 2017, 18, 480-487.

58 M. J. G. Peach, P. Benfield, T. Helgaker and D. J. Tozer, Excitation energies in density functional theory: An evaluation and a diagnostic test, J. Chem. Phys., 2008, 128, 044118.

59 M. Hoffmann, S. A. Mewes, S. Wieland, C. Popp and A. Dreuw, Electron-Hole Correlation as Unambiguous and Universal Classification for the Nature of Low-Lying $\pi \pi^{*}$ States of Nitrogen Heterocycles, J. Phys. Chem. Lett., 2019, 10, 6112-6117.

60 S. A. Mewes and A. Dreuw, Density-based descriptors and exciton analyses for visualizing and understanding the electronic structure of excited states, Phys. Chem. Chem. Phys., 2019, 21, 2843-2856.

61 M. Head-Gordon, A. M. Grana, D. Maurice and C. A. White, Analysis of Electronic Transitions as the Difference of Electron Attachment and Detachment Densities, J. Phys. Chem., 1995, 99, 14261-14270.

62 H. Nakai, Energy density analysis with Kohn-Sham orbitals, Chemical Physics Letters, 2002, 363, 73-79.

63 Y. Imamura, A. Takahashi and H. Nakai, Grid-based energy density analysis: Implementation and assessment, J. Chem. Phys., 2007, 126, 034103.

64 H. Nakai, H. Ohashi, Y. Imamura and Y. Kikuchi, Bond energy analysis revisited and designed toward a rigorous methodology, J. Chem. Phys., 2011, 135, 124105.

65 M. E. Casida, in Recent Advances in Density Functional Methods Part I., World Scientific, 1995, p. 155.

66 R. Bauernschmitt and R. Ahlrichs, Treatment of Electronic Excitations within the Adiabatic Approximation of Time Dependent Density Functional Theory, Chem. Phys. Lett., 1996, 256, 454-464. 
67 S. Hirata and M. Head-Gordon, Time-Dependent Density Functional Theory for Radicals, Chem. Phys. Lett., 1999, 302, 375-382.

68 A. Dreuw and M. Head-Gordon, Single-Reference ab Initio Methods for the Calculation of Excited States of Large Molecules, Chem. Rev., 2005, 105, 4009-4037.

69 M. Casida and M. Huix-Rotllant, Progress in Time-Dependent Density-Functional Theory, Ann. Rev. Phys. Chem., 2012, 63, 287-323.

70 J. Yang, Z. Pei, J. Deng, Y. Mao, Q. Wu, Z. Yang, B. Wang, C. M. Aikens, W. Liang and Y. Shao, Can We See the Energy Density? I. Insights from Real-Time Time-Dependent Density Functional Theory Simulations, Under Review.

71 J. Tao, J. P. Perdew, V. N. Staroverov and G. E. Scuseria, Climbing the Density Functional Ladder: Nonempirical MetaGeneralized Gradient Approximation Designed for Molecules and Solids, Phys. Rev. Lett., 2003, 91, 146401.

72 Y. Zhao and D. G. Truhlar, The M06 Suite of Density Functionals for Main Group Thermochemistry, Thermochemical Kinetics, Noncovalent Interactions, Excited states, and Transition Elements: Two New Functionals and Systematic Testing of Four M06-Class Functionals and 12 Other Functionals, Theor. Chem. Acc., 2008, 120, 215-241.

73 D. Maurice and M. Head-Gordon, Analytical Second Derivatives for Excited Electronic States Using the Single Excitation Configuration Interaction Method: Theory and Application to Benzo[a]pyrene and Chalcone, Mol. Phys., 1999, 96, 15331541.

74 F. Liu, Z. Gan, Y. Shao, C.-P. Hsu, A. Dreuw, M. Head-Gordon, B. T. Miller, B. R. Brooks, J.-G. Yu, T. R. Furlani and J. Kong, A Parallel Implementation of the Analytic Nuclear Gradient for Time-Dependent Density Functional Theory within the Tamm-Dancoff Approximation, Mol. Phys., 2010, 108, 27912800.

75 N. Holmberg and K. Laasonen, Efficient Constrained Density Functional Theory Implementation for Simulation of Condensed Phase Electron Transfer Reactions, J. Chem. Theory Comput., 2017, 13, 587-601.

76 Y. Mao, Q. Ge, P. R. Horn and M. Head-Gordon, On the Computational Characterization of Charge-Transfer Effects in Noncovalently Bound Molecular Complexes, J. Chem. Theory Comput., 2018, 14, 2401-2417.

77 Y. Shao, Y. Mei, D. Sundholm and V. R. I. Kaila, Benchmarking the Performance of Time-Dependent Density Functional Theory Methods on Biochromophores, J. Chem. Theory Comput., 2020, 16, 587-600.

78 A. Dreuw, J. L. Weisman and M. Head-Gordon, Long-range charge-transfer excited states in time-dependent density functional theory require non-local exchange, J. Chem. Phys., 2003, 119, 2943-2946.

79 M. A. Rohrdanz, K. M. Martins and J. M. Herbert, A longrange-corrected density functional that performs well for both ground-state properties and time-dependent density functional theory excitation energies, including charge-transfer excited states, J. Chem. Phys., 2009, 130, 054112.
80 J.-D. Chai and M. Head-Gordon, Long-Range Corrected Hybrid Density Functionals with Damped Atom-Atom Dispersion Corrections, Phys. Chem. Chem. Phys., 2008, 10, 6615.

81 R. Krishnan, J. S. Binkley, R. Seeger and J. A. Pople, SelfConsistent Molecular Orbital Methods. XX. A Basis Set for Correlated Wave Functions, J. Chem. Phys., 1980, 72, 650654.

82 Y.-Y. Cheng and Y.-J. Liu, What Exactly Is the Light Emitter of a Firefly?, J. Chem. Theory Comput., 2015, 11, 5360-5370.

83 Q. Sun, T. C. Berkelbach, N. S. Blunt, G. H. Booth, S. Guo, Z. Li, J. Liu, J. D. McClain, E. R. Sayfutyarova, S. Sharma, S. Wouters and G. K. Chan, PySCF: the Python-Based Simulations of Chemistry Framework, WIREs Comput. Mol. Sci., 2018, 8, e1340.

84 Y. Shao, Z. Gan, E. Epifanovsky, A. T. Gilbert, M. Wormit, J. Kussmann, A. W. Lange, A. Behn, J. Deng, X. Feng, D. Ghosh, M. Goldey, P. R. Horn, L. D. Jacobson, I. Kaliman, R. Z. Khaliullin, T. Kuś, A. Landau, J. Liu, E. I. Proynov, Y. M. Rhee, R. M. Richard, M. A. Rohrdanz, R. P. Steele, E. J. Sundstrom, H. L. Woodcock, P. M. Zimmerman, D. Zuev, B. Albrecht, E. Alguire, B. Austin, G. J. O. Beran, Y. A. Bernard, E. Berquist, K. Brandhorst, K. B. Bravaya, S. T. Brown, D. Casanova, C.-M. Chang, Y. Chen, S. H. Chien, K. D. Closser, D. L. Crittenden, M. Diedenhofen, R. A. DiStasio, H. Do, A. D. Dutoi, R. G. Edgar, S. Fatehi, L. Fusti-Molnar, A. Ghysels, A. Golubeva-Zadorozhnaya, J. Gomes, M. W. Hanson-Heine, P. H. Harbach, A. W. Hauser, E. G. Hohenstein, Z. C. Holden, T.-C. Jagau, H. Ji, B. Kaduk, K. Khistyaev, J. Kim, J. Kim, R. A. King, P. Klunzinger, D. Kosenkov, T. Kowalczyk, C. M. Krauter, K. U. Lao, A. D. Laurent, K. V. Lawler, S. V. Levchenko, C. Y. Lin, F. Liu, E. Livshits, R. C. Lochan, A. Luenser, P. Manohar, S. F. Manzer, S.-P. Mao, N. Mardirossian, A. V. Marenich, S. A. Maurer, N. J. Mayhall, E. Neuscamman, C. M. Oana, R. Olivares-Amaya, D. P. O'Neill, J. A. Parkhill, T. M. Perrine, R. Peverati, A. Prociuk, D. R. Rehn, E. Rosta, N. J. Russ, S. M. Sharada, S. Sharma, D. W. Small, A. Sodt, T. Stein, D. Stuck, Y.-C. Su, A. J. Thom, T. Tsuchimochi, V. Vanovschi, L. Vogt, O. Vydrov, T. Wang, M. A. Watson, J. Wenzel, A. White, C. F. Williams, J. Yang, S. Yeganeh, S. R. Yost, Z.-Q. You, I. Y. Zhang, X. Zhang, Y. Zhao, B. R. Brooks, G. K. Chan, D. M. Chipman, C. J. Cramer, W. A. Goddard, M. S. Gordon, W. J. Hehre, A. Klamt, H. F. Schaefer, M. W. Schmidt, C. D. Sherrill, D. G. Truhlar, A. Warshel, X. Xu, A. Aspuru-Guzik, R. Baer, A. T. Bell, N. A. Besley, J.-D. Chai, A. Dreuw, B. D. Dunietz, T. R. Furlani, S. R. Gwaltney, C.-P. Hsu, Y. Jung, J. Kong, D. S. Lambrecht, W. Liang, C. Ochsenfeld, V. A. Rassolov, L. V. Slipchenko, J. E. Subotnik, T. Van Voorhis, J. M. Herbert, A. I. Krylov, P. M. Gill and M. Head-Gordon, Advances in Molecular Quantum Chemistry Contained in the Q-Chem 4 Program Package, Mol. Phys., 2015, 113, 184-215.

85 C. Adamo and V. Barone, Toward Reliable Density Functional Methods Without Adjustable Parameters: The PBE0 Model, $J$. Chem. Phys., 1999, 110, 6158-6170.

86 W. J. Hehre, R. Ditchfield and J. A. Pople, Self-Consistent Molecular Orbital Methods. XII. Further Extensions of 
Gaussian-Type Basis Sets for Use in Molecular Orbital Studies of Organic Molecules, J. Chem. Phys., 1972, 56, 2257-2261.

87 P. C. Hariharan and J. A. Pople, The influence of polarization functions on molecular orbital hydrogenation energies, Theor. Chim. Acta, 1973, 28, 213-222.

88 J. P. Perdew, K. Burke and M. Ernzerhof, Generalized Gradient Approximation Made Simple, Phys. Rev. Lett., 1996, 77, 38653868.

89 O. Vahtras, J. Almlof and M. Feyereisen, Integral Approximations for LCAO-SCF Calculations, Chem. Phys. Lett., 1993, 213, 514-518.

90 K. Eichkorn, O. Treutler, H. Ohm, M. Haser and R. Ahlrichs, Auxiliary Basis Sets to Approximate Coulomb Potentials, Chem. Phys. Lett., 1995, 240, 283-290.

91 K. Eichkorn, F. Weigend, O. Treutler and R. Ahlrichs, Auxiliary Basis Sets for Main Row Atoms and Transition Metals and Their Use to Approximate Coulomb Potentials, Theor. Chem. Acta, 1997, 97, 119-124.

92 B. Dunlap, Robust and Variational Fitting: Removing the FourCenter Integrals from Center Stage in Quantum Chemistry, $J$. Mol. Struct. THEOCHEM, 2000, 529, 37-40.

93 B. Dunlap, Robust Variational Fitting: Gaspar's Variational Exchange Can Accurately Be Treated Analytically, J. Mol. Struct. THEOCHEM, 2000, 501-502, 221-228.
94 Y. Jung, A. Sodt, P. M. W. Gill and M. Head-Gordon, Auxiliary Basis Expansions for Large-Scale Electronic Structure Calculations, Proc. Natl. Acad. Sci. USA, 2005, 102, 6692-6697.

95 D. S. Hollman, H. F. Schaefer and E. F. Valeev, Semi-Exact Concentric Atomic Density Fitting: Reduced Cost and Increased Accuracy Compared to Standard Density Fitting, $J$. Chem. Phys., 2014, 140, 064109.

96 H. F. Schurkus, A. Luenser and C. Ochsenfeld, Almost ErrorFree Resolution-of-the-Identity Correlation Methods by Null Space Removal of the Particle-Hole Interactions, J. Chem. Phys., 2017, 146, 211106.

97 E. Proynov, Y. Shao and J. Kong, Efficient Self-Consistent DFT Calculation of Nondynamic Correlation Based on the B05 Method, Chem. Phys. Lett., 2010, 493, 381-385.

98 E. Proynov, F. Liu, Y. Shao and J. Kong, Improved SelfConsistent and Resolution-of-Identity Approximated Becke'05 Density Functional Model of Nondynamic Electron Correlation, J. Chem. Phys., 2012, 136, 034102.

99 Y. Mao, M. Head-Gordon and Y. Shao, Unraveling Substituent Effects on Frontier Orbitals of Conjugated Molecules Using an Absolutely Localized Molecular Orbital Based Analysis, Chem. Sci., 2018, 9, 8598-8607.

100 M. S. Gordon, D. G. Fedorov, S. R. Pruitt and L. V. Slipchenko, Fragmentation Methods: A Route to Accurate Calculations on Large Systems, Chem. Rev., 2012, 112, 632-672. 


\title{
Can We See the Energy Densities? II. Insights from Linear-Response Time-Dependent Density Functional Theory Calculations. Electronic Supplementary Information
}

\author{
Zheng Pei ${ }^{a, \#}$, Junjie Yang ${ }^{b, \#}$, Jingheng Deng ${ }^{b}$, Yuezhi $\mathrm{Mao}^{c}$, Qin $\mathrm{Wu}^{d}$, \\ Zhibo Yang ${ }^{b}$, Bin Wang ${ }^{e}$, Christine M. Aikens ${ }^{f}$, Wanzhen Liang*a ${ }^{* a}$, and Yihan Shao*b
}

August 2, 2020

${ }^{a}$ State Key Laboratory of Physical Chemistry of Solid Surfaces, Collaborative Innovation Center of Chemistry for Energy Materials, Fujian Provincial Key Laboratory of Theoretical and Computational Chemistry, and Department of Chemistry, College of Chemistry and Chemical Engineering, Xiamen University, Xiamen 361005, P. R. China. E-mail: liangwz@xmu.edu.cn

${ }^{b}$ Department of Chemistry and Biochemistry, University of Oklahoma, 101 Stephenson Pkwy, Norman, OK 73019, United States. E-mail: yihan.shao@ou.edu

${ }^{c}$ Department of Chemistry, Stanford University, Stanford, CA 94305, United States.

${ }^{d}$ Center for Functional Nanomaterials, Brookhaven National Laboratory, Upton, NY 11973, United States.

e Center for Interfacial Reaction Engineering and School of Chemical, Biological, and Materials Engineering, Gallogly College of Engineering, University of Oklahoma, Norman, OK 73019, United States.

$f$ Department of Chemistry, Kansas State University, Manhattan, KS 66506, United States.

\# These two authors contributed equally to this work. 


\section{$1 \quad$ Partition Results}

All charge and energy density calculations were carried out by PySCF. The only expections are FBH charges from LR-TDDFT- $\omega$ B97X-D relaxed difference densities, which were obtained from Q-CHEM calculations.

Table S1: LR-TDDFT Results of $\mathrm{C}_{2} \mathrm{H}_{4}-\mathrm{C}_{2} \mathrm{~F}_{4} \mathbf{F}$ Configuration using the PBE Functional.

\begin{tabular}{|c|c|c|c|c|c|c|c|c|c|c|}
\hline \multirow{2}{*}{ Basis } & \multirow{2}{*}{ ES\# } & \multirow{2}{*}{$\Lambda$} & \multirow{2}{*}{$\mathrm{S}_{\mathrm{DA}}$} & \multicolumn{2}{|c|}{$\mathrm{Q}_{\mathrm{FBH}}(\mathrm{au})$} & \multicolumn{2}{|c|}{$\omega_{\mathrm{FBH}, \mathrm{T}}(\mathrm{eV})$} & \multicolumn{2}{|c|}{$\omega_{\mathrm{FBH}}(\mathrm{eV})$} & \multirow{2}{*}{$\omega(\mathrm{eV})$} \\
\hline & & & & $\mathrm{C}_{2} \mathrm{H}_{4}$ & $\mathrm{C}_{2} \mathrm{~F}_{4}$ & $\mathrm{C}_{2} \mathrm{H}_{4}$ & $\mathrm{C}_{2} \mathrm{~F}_{4}$ & $\mathrm{C}_{2} \mathrm{H}_{4}$ & $\mathrm{C}_{2} \mathrm{~F}_{4}$ & \\
\hline \multirow{5}{*}{ 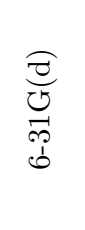 } & 1 & 0.058 & 0.018 & -0.998 & 0.998 & 34.909 & -69.402 & -0.415 & 5.425 & 5.009 \\
\hline & 2 & 0.625 & 0.630 & 0.001 & -0.001 & -0.037 & 13.541 & 0.002 & 6.788 & 6.790 \\
\hline & 3 & 0.060 & 0.035 & 0.998 & -0.998 & -28.689 & 69.787 & 6.411 & 0.403 & 6.814 \\
\hline & 4 & 0.017 & 0.021 & 0.998 & -0.998 & -28.675 & 83.323 & 6.401 & 1.155 & 7.556 \\
\hline & 5 & 0.024 & 0.018 & -0.999 & 0.999 & 25.114 & -69.386 & 2.665 & 5.414 & 8.078 \\
\hline \multirow{5}{*}{$\begin{array}{l}\widehat{\widetilde{J}} \\
+ \\
+ \\
\overrightarrow{0} \\
0\end{array}$} & 1 & 0.102 & 0.058 & -0.963 & 0.963 & 28.830 & -67.046 & -1.048 & 6.190 & 5.142 \\
\hline & 2 & 0.394 & 0.377 & -0.209 & 0.209 & 1.569 & -55.081 & 0.035 & 5.630 & 5.664 \\
\hline & 3 & 0.545 & 0.528 & -0.062 & 0.062 & 0.330 & -18.787 & 0.079 & 6.120 & 6.198 \\
\hline & 4 & 0.212 & 0.207 & 0.797 & -0.797 & -26.583 & 14.795 & 6.811 & -0.549 & 6.262 \\
\hline & 5 & 0.347 & 0.312 & -0.460 & 0.460 & 3.816 & -55.660 & 0.254 & 6.203 & 6.456 \\
\hline \multirow{5}{*}{$\begin{array}{l}\widehat{\partial} \\
\vec{E} \\
0 \\
= \\
0 \\
0 \\
0\end{array}$} & 1 & 0.084 & 0.029 & -0.995 & 0.995 & 34.293 & -69.793 & -0.832 & 5.860 & 5.028 \\
\hline & 2 & 0.092 & 0.056 & 0.993 & -0.993 & -28.790 & 70.381 & 6.734 & -0.010 & 6.725 \\
\hline & 3 & 0.625 & 0.629 & 0.000 & 0.000 & -0.045 & 12.413 & 0.012 & 6.727 & 6.739 \\
\hline & 4 & 0.096 & 0.078 & -0.981 & 0.981 & 16.717 & -69.313 & 1.136 & 5.871 & 7.006 \\
\hline & 5 & 0.035 & 0.044 & 0.993 & -0.993 & -28.752 & 82.550 & 6.716 & 0.682 & 7.398 \\
\hline \multirow{5}{*}{$\begin{array}{l}\overparen{\partial} \\
\overrightarrow{0} \\
0 \\
+ \\
+ \\
\vec{F} \\
\overrightarrow{0} \\
0\end{array}$} & 1 & 0.101 & 0.056 & -0.967 & 0.967 & 29.608 & -67.862 & -1.160 & 6.283 & 5.123 \\
\hline & 2 & 0.360 & 0.335 & -0.383 & 0.384 & 2.561 & -58.753 & -0.145 & 5.790 & 5.644 \\
\hline & 3 & 0.534 & 0.503 & -0.152 & 0.152 & 0.761 & -24.058 & 0.055 & 6.153 & 6.207 \\
\hline & 4 & 0.236 & 0.315 & 0.522 & -0.522 & -23.292 & 5.039 & 6.119 & 0.120 & 6.239 \\
\hline & 5 & 0.254 & 0.327 & -0.485 & 0.486 & 1.792 & -55.009 & 0.595 & 5.671 & 6.266 \\
\hline
\end{tabular}


Table S2: LR-TDDFT Results of $\mathrm{C}_{2} \mathrm{H}_{4}-\mathrm{C}_{2} \mathrm{~F}_{4} \mathbf{F}$ Configuration using the PBE0 Functional.

\begin{tabular}{|c|c|c|c|c|c|c|c|c|c|c|}
\hline \multirow{2}{*}{ Basis } & \multirow{2}{*}{ ES\# } & \multirow{2}{*}{$\Lambda$} & \multirow{2}{*}{$\mathrm{S}_{\mathrm{DA}}$} & \multicolumn{2}{|c|}{$\mathrm{Q}_{\mathrm{FBH}}(\mathrm{au})$} & \multicolumn{2}{|c|}{$\omega_{\mathrm{FBH}, \mathrm{T}}(\mathrm{eV})$} & \multicolumn{2}{|c|}{$\omega_{\mathrm{FBH}}(\mathrm{eV})$} & \multirow{2}{*}{$\omega(\mathrm{eV})$} \\
\hline & & & & $\mathrm{C}_{2} \mathrm{H}_{4}$ & $\mathrm{C}_{2} \mathrm{~F}_{4}$ & $\mathrm{C}_{2} \mathrm{H}_{4}$ & $\mathrm{C}_{2} \mathrm{~F}_{4}$ & $\mathrm{C}_{2} \mathrm{H}_{4}$ & $\mathrm{C}_{2} \mathrm{~F}_{4}$ & \\
\hline \multirow{5}{*}{ 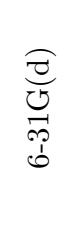 } & 1 & 0.092 & 0.042 & -0.997 & 0.997 & 32.978 & -66.022 & 0.315 & 6.698 & 7.012 \\
\hline & 2 & 0.623 & 0.631 & 0.000 & 0.000 & -0.012 & 15.975 & -0.003 & 7.129 & 7.125 \\
\hline & 3 & 0.163 & 0.311 & 0.930 & -0.930 & -26.069 & 61.986 & 7.274 & 0.952 & 8.226 \\
\hline & 4 & 0.787 & 0.950 & 0.067 & -0.067 & 1.570 & 4.361 & 7.691 & 0.715 & 8.406 \\
\hline & 5 & 0.534 & 0.586 & 0.001 & -0.001 & 5.829 & 0.029 & 8.498 & 0.010 & 8.508 \\
\hline \multirow{5}{*}{$\begin{array}{l}\underset{\overbrace{}}{0} \\
+ \\
+ \\
0 \\
0\end{array}$} & 1 & 0.361 & 0.409 & -0.134 & 0.134 & 0.816 & -50.095 & 0.086 & 6.362 & 6.447 \\
\hline & 2 & 0.437 & 0.575 & -0.022 & 0.022 & 0.085 & -4.582 & 0.037 & 6.668 & 6.705 \\
\hline & 3 & 0.162 & 0.164 & -0.867 & 0.867 & 21.596 & -61.995 & -0.438 & 7.284 & 6.845 \\
\hline & 4 & 0.243 & 0.322 & 0.474 & -0.474 & -22.956 & 6.358 & 7.327 & -0.204 & 7.123 \\
\hline & 5 & 0.276 & 0.419 & -0.271 & 0.271 & 4.285 & -44.914 & 0.516 & 6.997 & 7.512 \\
\hline \multirow{5}{*}{$\begin{array}{l}\stackrel{2}{2} \\
\stackrel{0}{0} \\
0 \\
\vec{~} \\
0 \\
0\end{array}$} & 1 & 0.135 & 0.067 & -0.992 & 0.992 & 32.029 & -66.136 & -0.095 & 7.067 & 6.972 \\
\hline & 2 & 0.620 & 0.630 & 0.000 & 0.000 & -0.015 & 14.972 & -0.001 & 7.077 & 7.075 \\
\hline & 3 & 0.590 & 0.776 & 0.416 & -0.416 & -10.663 & 27.599 & 7.671 & 0.388 & 8.059 \\
\hline & 4 & 0.353 & 0.645 & 0.575 & -0.575 & -14.922 & 39.096 & 7.789 & 0.407 & 8.195 \\
\hline & 5 & 0.550 & 0.631 & 0.002 & -0.002 & 4.692 & 0.065 & 8.219 & 0.019 & 8.238 \\
\hline \multirow{5}{*}{ 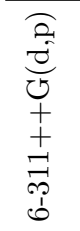 } & 1 & 0.302 & 0.405 & -0.179 & 0.179 & 0.894 & -51.070 & 0.047 & 6.432 & 6.479 \\
\hline & 2 & 0.368 & 0.579 & -0.025 & 0.025 & 0.084 & -3.867 & 0.026 & 6.702 & 6.728 \\
\hline & 3 & 0.171 & 0.158 & -0.883 & 0.883 & 22.745 & -62.888 & -0.530 & 7.377 & 6.847 \\
\hline & 4 & 0.252 & 0.310 & 0.240 & -0.240 & -22.340 & 2.446 & 6.969 & -0.071 & 6.898 \\
\hline & 5 & 0.287 & 0.210 & -0.694 & 0.694 & 3.955 & -60.927 & -0.051 & 7.482 & 7.430 \\
\hline
\end{tabular}


Table S3: LR-TDDFT Results of $\mathrm{C}_{2} \mathrm{H}_{4}-\mathrm{C}_{2} \mathrm{~F}_{4} \mathbf{F}$ Configuration using the $\omega$ B97X-D Functional.

\begin{tabular}{|c|c|c|c|c|c|c|c|c|c|c|}
\hline \multirow{2}{*}{ Basis } & \multirow{2}{*}{ ES\# } & \multirow{2}{*}{$\Lambda$} & \multirow{2}{*}{$\mathrm{S}_{\mathrm{DA}}$} & \multicolumn{2}{|c|}{$\mathrm{Q}_{\mathrm{FBH}}(\mathrm{au})$} & \multicolumn{2}{|c|}{$\omega_{\mathrm{FBH}, \mathrm{T}}(\mathrm{eV})$} & \multicolumn{2}{|c|}{$\omega_{\mathrm{FBH}}(\mathrm{eV})$} & \multirow{2}{*}{$\omega(\mathrm{eV})$} \\
\hline & & & & $\mathrm{C}_{2} \mathrm{H}_{4}$ & $\mathrm{C}_{2} \mathrm{~F}_{4}$ & $\mathrm{C}_{2} \mathrm{H}_{4}$ & $\mathrm{C}_{2} \mathrm{~F}_{4}$ & $\mathrm{C}_{2} \mathrm{H}_{4}$ & $\mathrm{C}_{2} \mathrm{~F}_{4}$ & \\
\hline \multirow{5}{*}{ 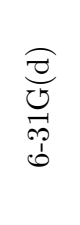 } & 1 & 0.622 & 0.631 & 0.000 & 0.000 & -0.007 & 16.853 & -0.003 & 7.179 & 7.175 \\
\hline & 2 & 0.862 & 0.956 & -0.007 & 0.007 & 3.955 & -0.717 & 7.604 & 0.746 & 8.350 \\
\hline & 3 & 0.534 & 0.578 & 0.001 & -0.001 & 5.931 & 0.017 & 8.562 & 0.010 & 8.572 \\
\hline & 4 & 0.815 & 0.939 & -0.035 & 0.035 & 1.562 & -5.014 & 0.805 & 7.793 & 8.597 \\
\hline & 5 & 0.156 & 0.223 & -0.953 & 0.953 & 31.248 & -62.876 & 1.122 & 7.637 & 8.758 \\
\hline \multirow{5}{*}{ 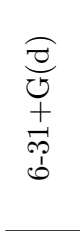 } & 1 & 0.323 & 0.428 & -0.099 & 0.099 & 0.583 & -48.303 & 0.097 & 6.701 & 6.797 \\
\hline & 2 & 0.385 & 0.597 & -0.013 & 0.013 & 0.047 & 2.353 & 0.022 & 6.843 & 6.864 \\
\hline & 3 & 0.267 & 0.396 & 0.176 & -0.176 & -19.656 & 1.592 & 7.489 & 0.066 & 7.556 \\
\hline & 4 & 0.716 & 0.831 & 0.040 & -0.040 & -7.177 & -0.056 & 7.398 & 0.252 & 7.650 \\
\hline & 5 & 0.281 & 0.423 & -0.228 & 0.228 & 2.725 & -42.922 & 0.137 & 7.693 & 7.830 \\
\hline \multirow{5}{*}{ 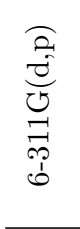 } & 1 & 0.616 & 0.631 & 0.000 & 0.000 & -0.010 & 16.013 & -0.003 & 7.138 & 7.135 \\
\hline & 2 & 0.845 & 0.942 & -0.002 & 0.002 & 2.647 & -0.302 & 7.808 & 0.257 & 8.064 \\
\hline & 3 & 0.551 & 0.606 & 0.001 & -0.001 & 5.034 & 0.035 & 8.289 & 0.018 & 8.308 \\
\hline & 4 & 0.691 & 0.898 & -0.158 & 0.158 & 4.633 & -12.355 & 0.355 & 8.172 & 8.527 \\
\hline & 5 & 0.393 & 0.414 & 0.005 & -0.005 & -11.055 & 0.075 & 8.518 & 0.024 & 8.541 \\
\hline \multirow{5}{*}{$\begin{array}{l}\widehat{a} \\
\stackrel{0}{0} \\
0 \\
+ \\
+ \\
\vec{~} \\
\overrightarrow{0} \\
0\end{array}$} & 1 & 0.264 & 0.433 & -0.107 & 0.107 & 0.531 & -48.762 & 0.094 & 6.727 & 6.821 \\
\hline & 2 & 0.410 & 0.600 & -0.012 & 0.012 & 0.038 & 3.105 & 0.016 & 6.868 & 6.883 \\
\hline & 3 & 0.239 & 0.327 & 0.101 & -0.101 & -21.287 & 0.491 & 7.137 & 0.056 & 7.192 \\
\hline & 4 & 0.608 & 0.844 & 0.039 & -0.039 & -6.250 & 0.118 & 7.402 & 0.205 & 7.607 \\
\hline & 5 & 0.186 & 0.358 & 0.059 & -0.059 & -20.640 & 0.390 & 7.770 & 0.080 & 7.850 \\
\hline
\end{tabular}


Table S4: LR-TDDFT Results of $\mathrm{C}_{2} \mathrm{H}_{4}-\mathrm{C}_{2} \mathrm{~F}_{4} \mathbf{P} 1$ Configuration using the PBE Functional.

\begin{tabular}{|c|c|c|c|c|c|c|c|c|c|c|}
\hline \multirow{2}{*}{ Basis } & \multirow{2}{*}{ ES\# } & \multirow{2}{*}{$\Lambda$} & \multirow{2}{*}{$\mathrm{S}_{\mathrm{DA}}$} & \multicolumn{2}{|c|}{$\mathrm{Q}_{\mathrm{FBH}}(\mathrm{au})$} & \multicolumn{2}{|c|}{$\omega_{\mathrm{FBH}, \mathrm{T}}(\mathrm{eV})$} & \multicolumn{2}{|c|}{$\omega_{\mathrm{FBH}}(\mathrm{eV})$} & \multirow{2}{*}{$\omega(\mathrm{eV})$} \\
\hline & & & & $\mathrm{C}_{2} \mathrm{H}_{4}$ & $\mathrm{C}_{2} \mathrm{~F}_{4}$ & $\mathrm{C}_{2} \mathrm{H}_{4}$ & $\mathrm{C}_{2} \mathrm{~F}_{4}$ & $\mathrm{C}_{2} \mathrm{H}_{4}$ & $\mathrm{C}_{2} \mathrm{~F}_{4}$ & \\
\hline \multirow{5}{*}{ 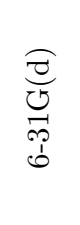 } & 1 & 0.009 & 0.003 & -0.988 & 0.988 & 34.946 & -69.455 & -0.322 & 5.538 & 5.215 \\
\hline & 2 & 0.009 & 0.004 & 0.988 & -0.988 & -28.727 & 69.881 & 6.317 & 0.291 & 6.609 \\
\hline & 3 & 0.619 & 0.620 & -0.032 & 0.032 & 0.701 & 10.177 & 0.060 & 6.681 & 6.740 \\
\hline & 4 & 0.070 & 0.069 & 0.965 & -0.965 & -28.245 & 81.017 & 6.363 & 0.944 & 7.307 \\
\hline & 5 & 0.374 & 0.299 & -0.778 & 0.778 & 19.768 & -54.262 & 1.892 & 6.266 & 8.158 \\
\hline \multirow{5}{*}{$\begin{array}{l}\text { త્ర } \\
+ \\
+ \\
0 \\
0 \\
0\end{array}$} & 1 & 0.055 & 0.019 & -0.974 & 0.974 & 29.339 & -67.360 & -0.910 & 6.283 & 5.372 \\
\hline & 2 & 0.407 & 0.388 & -0.168 & 0.168 & 1.882 & -53.440 & 0.016 & 5.682 & 5.698 \\
\hline & 3 & 0.164 & 0.158 & 0.826 & -0.826 & -26.415 & 16.722 & 6.683 & -0.651 & 6.032 \\
\hline & 4 & 0.532 & 0.510 & -0.118 & 0.118 & 1.326 & -24.072 & -0.005 & 6.170 & 6.164 \\
\hline & 5 & 0.057 & 0.020 & 0.976 & -0.976 & -28.076 & 68.547 & 6.660 & -0.409 & 6.251 \\
\hline \multirow{5}{*}{$\begin{array}{l}\stackrel{2}{2} \\
\stackrel{0}{0} \\
0 \\
\vec{~} \\
0 \\
0\end{array}$} & 1 & 0.013 & 0.004 & -0.984 & 0.984 & 34.390 & -69.882 & -0.708 & 5.975 & 5.267 \\
\hline & 2 & 0.014 & 0.006 & 0.984 & -0.984 & -28.878 & 70.652 & 6.611 & -0.121 & 6.490 \\
\hline & 3 & 0.580 & 0.563 & -0.179 & 0.179 & 3.017 & -6.558 & 0.139 & 6.415 & 6.554 \\
\hline & 4 & 0.147 & 0.144 & 0.869 & -0.869 & -27.010 & 70.084 & 6.707 & 0.311 & 7.018 \\
\hline & 5 & 0.356 & 0.333 & -0.706 & 0.706 & 12.591 & -48.878 & 0.810 & 6.478 & 7.288 \\
\hline \multirow{5}{*}{ 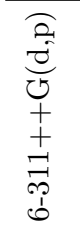 } & 1 & 0.054 & 0.019 & -0.975 & 0.975 & 30.110 & -68.142 & -1.020 & 6.372 & 5.352 \\
\hline & 2 & 0.395 & 0.370 & -0.253 & 0.253 & 2.291 & -55.139 & -0.067 & 5.774 & 5.707 \\
\hline & 3 & 0.180 & 0.175 & 0.756 & -0.756 & -26.486 & 15.921 & 6.699 & -0.658 & 6.041 \\
\hline & 4 & 0.526 & 0.491 & -0.170 & 0.170 & 1.413 & -29.529 & -0.043 & 6.231 & 6.188 \\
\hline & 5 & 0.057 & 0.021 & 0.977 & -0.977 & -28.459 & 69.242 & 6.749 & -0.500 & 6.250 \\
\hline
\end{tabular}


Table S5: LR-TDDFT Results of $\mathrm{C}_{2} \mathrm{H}_{4}-\mathrm{C}_{2} \mathrm{~F}_{4}$ P1 Configuration using the PBE0 Functional.

\begin{tabular}{|c|c|c|c|c|c|c|c|c|c|c|}
\hline \multirow{2}{*}{ Basis } & \multirow{2}{*}{ ES\# } & \multirow{2}{*}{$\Lambda$} & \multirow{2}{*}{$\mathrm{S}_{\mathrm{DA}}$} & \multicolumn{2}{|c|}{$\mathrm{Q}_{\mathrm{FBH}}(\mathrm{au})$} & \multicolumn{2}{|c|}{$\omega_{\mathrm{FBH}, \mathrm{T}}(\mathrm{eV})$} & \multicolumn{2}{|c|}{$\omega_{\mathrm{FBH}}(\mathrm{eV})$} & \multirow{2}{*}{$\omega(\mathrm{eV})$} \\
\hline & & & & $\mathrm{C}_{2} \mathrm{H}_{4}$ & $\mathrm{C}_{2} \mathrm{~F}_{4}$ & $\mathrm{C}_{2} \mathrm{H}_{4}$ & $\mathrm{C}_{2} \mathrm{~F}_{4}$ & $\mathrm{C}_{2} \mathrm{H}_{4}$ & $\mathrm{C}_{2} \mathrm{~F}_{4}$ & \\
\hline \multirow{5}{*}{$\begin{array}{l}\underset{Ð}{0} \\
\underset{0}{0} \\
0 \\
b\end{array}$} & 1 & 0.611 & 0.628 & -0.010 & 0.010 & 0.194 & 14.812 & 0.026 & 7.074 & 7.099 \\
\hline & 2 & 0.015 & 0.006 & -0.990 & 0.990 & 33.110 & -66.324 & 0.426 & 6.819 & 7.244 \\
\hline & 3 & 0.015 & 0.018 & 0.990 & -0.990 & -28.145 & 66.751 & 7.194 & 0.848 & 8.042 \\
\hline & 4 & 0.879 & 0.958 & 0.000 & 0.000 & 3.521 & -0.384 & 7.502 & 0.884 & 8.386 \\
\hline & 5 & 0.533 & 0.597 & 0.002 & -0.002 & 5.757 & 0.145 & 8.520 & -0.012 & 8.508 \\
\hline \multirow{5}{*}{$\begin{array}{l}\underset{\partial}{0} \\
+ \\
+ \\
0 \\
0 \\
0\end{array}$} & 1 & 0.381 & 0.418 & -0.100 & 0.101 & 0.975 & -48.722 & 0.057 & 6.420 & 6.476 \\
\hline & 2 & 0.410 & 0.575 & -0.040 & 0.040 & 0.409 & -5.725 & 0.014 & 6.694 & 6.707 \\
\hline & 3 & 0.207 & 0.259 & 0.597 & -0.597 & -23.290 & 10.649 & 7.249 & -0.299 & 6.950 \\
\hline & 4 & 0.165 & 0.045 & -0.973 & 0.973 & 25.436 & -64.515 & -0.269 & 7.433 & 7.163 \\
\hline & 5 & 0.295 & 0.393 & -0.152 & 0.152 & 1.197 & -43.491 & 0.124 & 7.335 & 7.458 \\
\hline \multirow{5}{*}{ 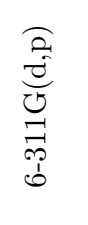 } & 1 & 0.497 & 0.616 & -0.039 & 0.039 & 0.553 & 10.231 & 0.049 & 6.952 & 7.001 \\
\hline & 2 & 0.025 & 0.010 & -0.987 & 0.987 & 32.320 & -66.576 & 0.048 & 7.191 & 7.239 \\
\hline & 3 & 0.028 & 0.039 & 0.985 & -0.985 & -28.161 & 67.178 & 7.422 & 0.498 & 7.921 \\
\hline & 4 & 0.250 & 0.397 & 0.308 & -0.308 & -16.118 & 17.695 & 7.710 & 0.380 & 8.090 \\
\hline & 5 & 0.864 & 0.945 & 0.002 & -0.002 & 2.436 & -0.002 & 7.879 & 0.234 & 8.114 \\
\hline \multirow{5}{*}{ 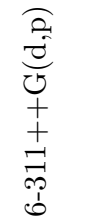 } & 1 & 0.359 & 0.417 & -0.139 & 0.139 & 1.130 & -48.817 & 0.024 & 6.485 & 6.509 \\
\hline & 2 & 0.384 & 0.579 & -0.031 & 0.031 & 0.288 & -5.908 & 0.007 & 6.728 & 6.734 \\
\hline & 3 & 0.250 & 0.271 & 0.416 & -0.415 & -23.203 & 7.259 & 7.068 & -0.235 & 6.833 \\
\hline & 4 & 0.245 & 0.047 & -0.975 & 0.975 & 26.273 & -65.082 & -0.360 & 7.517 & 7.158 \\
\hline & 5 & 0.263 & 0.252 & 0.298 & -0.298 & -23.019 & 4.821 & 7.460 & -0.120 & 7.339 \\
\hline
\end{tabular}


Table S6: LR-TDDFT Results of $\mathrm{C}_{2} \mathrm{H}_{4}-\mathrm{C}_{2} \mathrm{~F}_{4} \mathbf{P} 1$ Configuration using the $\omega$ B97X-D Functional.

\begin{tabular}{|c|c|c|c|c|c|c|c|c|c|c|}
\hline \multirow{2}{*}{ Basis } & \multirow{2}{*}{ ES\# } & \multirow{2}{*}{$\Lambda$} & \multirow{2}{*}{$\mathrm{S}_{\mathrm{DA}}$} & \multicolumn{2}{|c|}{$\mathrm{Q}_{\mathrm{FBH}}(\mathrm{au})$} & \multicolumn{2}{|c|}{$\omega_{\mathrm{FBH}, \mathrm{T}}(\mathrm{eV})$} & \multicolumn{2}{|c|}{$\omega_{\mathrm{FBH}}(\mathrm{eV})$} & \multirow{2}{*}{$\omega(\mathrm{eV})$} \\
\hline & & & & $\mathrm{C}_{2} \mathrm{H}_{4}$ & $\mathrm{C}_{2} \mathrm{~F}_{4}$ & $\mathrm{C}_{2} \mathrm{H}_{4}$ & $\mathrm{C}_{2} \mathrm{~F}_{4}$ & $\mathrm{C}_{2} \mathrm{H}_{4}$ & $\mathrm{C}_{2} \mathrm{~F}_{4}$ & \\
\hline \multirow{5}{*}{ 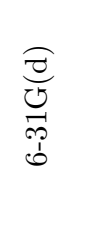 } & 1 & 0.610 & 0.630 & -0.005 & 0.005 & 0.084 & 16.287 & 0.018 & 7.143 & 7.161 \\
\hline & 2 & 0.880 & 0.957 & 0.000 & 0.000 & 3.780 & -0.273 & 7.596 & 0.752 & 8.348 \\
\hline & 3 & 0.536 & 0.579 & -0.001 & 0.001 & 5.966 & -0.059 & 8.591 & -0.019 & 8.572 \\
\hline & 4 & 0.861 & 0.942 & -0.001 & 0.001 & 0.384 & -2.637 & 0.776 & 7.822 & 8.598 \\
\hline & 5 & 0.018 & 0.015 & -0.991 & 0.991 & 32.912 & -66.799 & 1.283 & 7.724 & 9.005 \\
\hline \multirow{5}{*}{$\begin{array}{l}\underset{\partial}{\tilde{J}} \\
+ \\
\stackrel{+}{0} \\
0 \\
0\end{array}$} & 1 & 0.331 & 0.434 & -0.047 & 0.047 & 0.404 & -47.652 & 0.063 & 6.766 & 6.829 \\
\hline & 2 & 0.395 & 0.602 & -0.031 & 0.031 & 0.279 & 3.502 & 0.034 & 6.849 & 6.883 \\
\hline & 3 & 0.362 & 0.373 & 0.184 & -0.184 & -19.147 & 3.108 & 7.491 & 0.066 & 7.557 \\
\hline & 4 & 0.595 & 0.838 & 0.010 & -0.010 & -6.976 & 0.059 & 7.538 & 0.114 & 7.652 \\
\hline & 5 & 0.258 & 0.445 & -0.061 & 0.061 & 0.458 & -37.046 & 0.103 & 7.867 & 7.969 \\
\hline \multirow{5}{*}{ 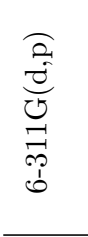 } & 1 & 0.475 & 0.626 & -0.014 & 0.014 & 0.187 & 14.135 & 0.032 & 7.068 & 7.100 \\
\hline & 2 & 0.864 & 0.943 & 0.001 & -0.001 & 2.655 & -0.061 & 7.854 & 0.214 & 8.068 \\
\hline & 3 & 0.555 & 0.607 & -0.001 & 0.001 & 5.100 & -0.043 & 8.328 & -0.019 & 8.309 \\
\hline & 4 & 0.291 & 0.407 & 0.088 & -0.088 & -12.039 & 3.448 & 8.253 & 0.281 & 8.535 \\
\hline & 5 & 0.849 & 0.933 & -0.001 & 0.001 & 0.079 & -2.768 & 0.230 & 8.313 & 8.543 \\
\hline \multirow{5}{*}{$\begin{array}{l}\text { a } \\
\overrightarrow{0} \\
\text { v } \\
+ \\
\pm \\
\pm \\
\overrightarrow{0} \\
0 \\
0\end{array}$} & 1 & 0.283 & 0.437 & -0.070 & 0.070 & 0.521 & -48.076 & 0.056 & 6.791 & 6.847 \\
\hline & 2 & 0.366 & 0.604 & -0.022 & 0.022 & 0.180 & 3.638 & 0.017 & 6.883 & 6.900 \\
\hline & 3 & 0.277 & 0.320 & 0.097 & -0.097 & -21.502 & 1.453 & 7.180 & 0.043 & 7.222 \\
\hline & 4 & 0.624 & 0.850 & 0.009 & -0.009 & -5.985 & 0.049 & 7.502 & 0.108 & 7.610 \\
\hline & 5 & 0.191 & 0.253 & 0.096 & -0.096 & -21.965 & 0.637 & 7.748 & 0.170 & 7.918 \\
\hline
\end{tabular}


Table S7: LR-TDDFT Results of $\mathrm{C}_{2} \mathrm{H}_{4}-\mathrm{C}_{2} \mathrm{~F}_{4}$ P2 Configuration using the PBE Functional.

\begin{tabular}{|c|c|c|c|c|c|c|c|c|c|c|}
\hline \multirow{2}{*}{ Basis } & \multirow{2}{*}{$\mathrm{ES} \#$} & \multirow{2}{*}{$\Lambda$} & \multirow{2}{*}{$\mathrm{S}_{\mathrm{DA}}$} & \multicolumn{2}{|c|}{$\mathrm{Q}_{\mathrm{FBH}}(\mathrm{au})$} & \multicolumn{2}{|c|}{$\omega_{\mathrm{FBH}, \mathrm{T}}(\mathrm{eV})$} & \multicolumn{2}{|c|}{$\omega_{\mathrm{FBH}}(\mathrm{eV})$} & \multirow{2}{*}{$\omega(\mathrm{eV})$} \\
\hline & & & & $\mathrm{C}_{2} \mathrm{H}_{4}$ & $\mathrm{C}_{2} \mathrm{~F}_{4}$ & $\mathrm{C}_{2} \mathrm{H}_{4}$ & $\mathrm{C}_{2} \mathrm{~F}_{4}$ & $\mathrm{C}_{2} \mathrm{H}_{4}$ & $\mathrm{C}_{2} \mathrm{~F}_{4}$ & \\
\hline \multirow{5}{*}{ 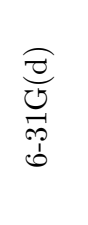 } & 1 & 0.003 & 0.001 & -0.998 & 0.998 & 34.960 & -69.463 & -0.339 & 5.491 & 5.151 \\
\hline & 2 & 0.003 & 0.001 & 0.998 & -0.998 & -28.735 & 69.879 & 6.336 & 0.336 & 6.673 \\
\hline & 3 & 0.625 & 0.629 & -0.002 & 0.002 & 0.034 & 13.254 & 0.008 & 6.782 & 6.789 \\
\hline & 4 & 0.013 & 0.015 & 0.997 & -0.997 & -28.708 & 83.237 & 6.343 & 1.069 & 7.412 \\
\hline & 5 & 0.532 & 0.574 & 0.000 & 0.000 & 6.378 & -0.004 & 8.180 & -0.001 & 8.178 \\
\hline \multirow{5}{*}{$\begin{array}{l}\underset{\partial}{0} \\
+ \\
+ \\
\overrightarrow{0} \\
0\end{array}$} & 1 & 0.025 & 0.020 & -0.981 & 0.981 & 29.215 & -67.336 & -0.935 & 6.261 & 5.326 \\
\hline & 2 & 0.411 & 0.393 & -0.099 & 0.099 & 0.941 & -53.407 & 0.039 & 5.698 & 5.737 \\
\hline & 3 & 0.093 & 0.088 & 0.907 & -0.907 & -27.342 & 16.784 & 6.714 & -0.603 & 6.111 \\
\hline & 4 & 0.549 & 0.533 & -0.048 & 0.048 & 0.416 & -17.770 & 0.056 & 6.155 & 6.211 \\
\hline & 5 & 0.011 & 0.004 & 0.990 & -0.990 & -28.100 & 68.618 & 6.675 & -0.380 & 6.296 \\
\hline \multirow{5}{*}{ 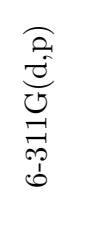 } & 1 & 0.006 & 0.002 & -0.996 & 0.996 & 34.408 & -69.898 & -0.730 & 5.928 & 5.198 \\
\hline & 2 & 0.007 & 0.003 & 0.995 & -0.995 & -28.890 & 70.655 & 6.635 & -0.075 & 6.560 \\
\hline & 3 & 0.622 & 0.625 & -0.014 & 0.014 & 0.204 & 10.886 & 0.030 & 6.694 & 6.724 \\
\hline & 4 & 0.131 & 0.091 & -0.943 & 0.943 & 16.150 & -67.607 & 1.082 & 6.045 & 7.126 \\
\hline & 5 & 0.032 & 0.036 & 0.986 & -0.986 & -28.749 & 81.686 & 6.657 & 0.558 & 7.215 \\
\hline \multirow{5}{*}{ 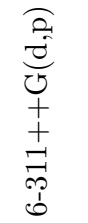 } & 1 & 0.022 & 0.018 & -0.982 & 0.982 & 29.994 & -68.128 & -1.044 & 6.350 & 5.306 \\
\hline & 2 & 0.394 & 0.367 & -0.212 & 0.212 & 1.638 & -55.816 & -0.054 & 5.810 & 5.756 \\
\hline & 3 & 0.124 & 0.119 & 0.823 & -0.823 & -27.249 & 15.489 & 6.728 & -0.596 & 6.132 \\
\hline & 4 & 0.211 & 0.194 & -0.735 & 0.735 & 5.219 & -63.618 & -0.136 & 6.348 & 6.212 \\
\hline & 5 & 0.539 & 0.515 & -0.113 & 0.113 & 0.721 & -21.591 & 0.047 & 6.169 & 6.216 \\
\hline
\end{tabular}


Table S8: LR-TDDFT Results of $\mathrm{C}_{2} \mathrm{H}_{4}-\mathrm{C}_{2} \mathrm{~F}_{4}$ P2 Configuration using the PBE0 Functional.

\begin{tabular}{|c|c|c|c|c|c|c|c|c|c|c|}
\hline \multirow{2}{*}{ Basis } & \multirow{2}{*}{ ES\# } & \multirow{2}{*}{$\Lambda$} & \multirow{2}{*}{$\mathrm{S}_{\mathrm{DA}}$} & \multicolumn{2}{|c|}{$\mathrm{Q}_{\mathrm{FBH}}(\mathrm{au})$} & \multicolumn{2}{|c|}{$\omega_{\mathrm{FBH}, \mathrm{T}}(\mathrm{eV})$} & \multicolumn{2}{|c|}{$\omega_{\mathrm{FBH}}(\mathrm{eV})$} & \multirow{2}{*}{$\omega(\mathrm{eV})$} \\
\hline & & & & $\mathrm{C}_{2} \mathrm{H}_{4}$ & $\mathrm{C}_{2} \mathrm{~F}_{4}$ & $\mathrm{C}_{2} \mathrm{H}_{4}$ & $\mathrm{C}_{2} \mathrm{~F}_{4}$ & $\mathrm{C}_{2} \mathrm{H}_{4}$ & $\mathrm{C}_{2} \mathrm{~F}_{4}$ & \\
\hline \multirow{5}{*}{ 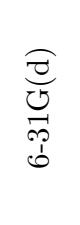 } & 1 & 0.623 & 0.631 & -0.001 & 0.001 & 0.013 & 15.848 & 0.005 & 7.121 & 7.126 \\
\hline & 2 & 0.005 & 0.003 & -0.999 & 0.999 & 33.086 & -66.347 & 0.466 & 6.835 & 7.301 \\
\hline & 3 & 0.005 & 0.013 & 0.998 & -0.998 & -28.155 & 66.737 & 7.274 & 0.948 & 8.222 \\
\hline & 4 & 0.882 & 0.959 & 0.000 & 0.000 & 3.672 & -0.238 & 7.819 & 0.580 & 8.399 \\
\hline & 5 & 0.536 & 0.588 & 0.000 & 0.000 & 5.876 & 0.003 & 8.516 & -0.001 & 8.515 \\
\hline \multirow{5}{*}{$\begin{array}{l}\underset{\circlearrowright}{\tilde{\mho}} \\
+ \\
\underset{0}{+} \\
0\end{array}$} & 1 & 0.381 & 0.418 & -0.048 & 0.048 & 0.380 & -49.181 & 0.046 & 6.444 & 6.489 \\
\hline & 2 & 0.454 & 0.577 & -0.016 & 0.016 & 0.118 & -4.107 & 0.034 & 6.681 & 6.715 \\
\hline & 3 & 0.132 & 0.230 & 0.616 & -0.616 & -23.729 & 9.127 & 7.385 & -0.213 & 7.172 \\
\hline & 4 & 0.054 & 0.055 & -0.954 & 0.954 & 24.172 & -64.364 & -0.264 & 7.468 & 7.204 \\
\hline & 5 & 0.284 & 0.394 & -0.203 & 0.203 & 1.813 & -43.499 & 0.090 & 7.363 & 7.453 \\
\hline \multirow{5}{*}{ 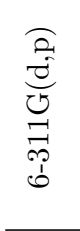 } & 1 & 0.611 & 0.629 & -0.004 & 0.004 & 0.046 & 14.460 & 0.014 & 7.055 & 7.069 \\
\hline & 2 & 0.010 & 0.005 & -0.996 & 0.996 & 32.293 & -66.607 & 0.083 & 7.206 & 7.288 \\
\hline & 3 & 0.069 & 0.280 & 0.921 & -0.921 & -25.878 & 62.110 & 7.543 & 0.561 & 8.105 \\
\hline & 4 & 0.784 & 0.927 & 0.076 & -0.076 & 0.192 & 5.080 & 7.949 & 0.175 & 8.124 \\
\hline & 5 & 0.552 & 0.639 & 0.001 & -0.001 & 4.703 & 0.050 & 8.244 & 0.003 & 8.247 \\
\hline \multirow{5}{*}{ 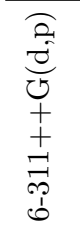 } & 1 & 0.327 & 0.417 & -0.072 & 0.072 & 0.467 & -49.833 & 0.020 & 6.517 & 6.537 \\
\hline & 2 & 0.355 & 0.579 & -0.024 & 0.024 & 0.140 & -3.860 & 0.032 & 6.702 & 6.733 \\
\hline & 3 & 0.187 & 0.284 & 0.213 & -0.213 & -22.224 & 2.807 & 6.988 & -0.068 & 6.920 \\
\hline & 4 & 0.055 & 0.048 & -0.960 & 0.960 & 25.210 & -64.985 & -0.353 & 7.555 & 7.202 \\
\hline & 5 & 0.208 & 0.213 & 0.464 & -0.464 & -24.148 & 7.010 & 7.507 & -0.167 & 7.341 \\
\hline
\end{tabular}


Table S9: LR-TDDFT Results of $\mathrm{C}_{2} \mathrm{H}_{4}-\mathrm{C}_{2} \mathrm{~F}_{4}$ P2 Configuration using the $\omega$ B97X-D Functional.

\begin{tabular}{|c|c|c|c|c|c|c|c|c|c|c|}
\hline \multirow{2}{*}{ Basis } & \multirow{2}{*}{ ES\# } & \multirow{2}{*}{$\Lambda$} & \multirow{2}{*}{$\mathrm{S}_{\mathrm{DA}}$} & \multicolumn{2}{|c|}{$\mathrm{Q}_{\mathrm{FBH}}(\mathrm{au})$} & \multicolumn{2}{|c|}{$\omega_{\mathrm{FBH}, \mathrm{T}}(\mathrm{eV})$} & \multicolumn{2}{|c|}{$\omega_{\mathrm{FBH}}(\mathrm{eV})$} & \multirow{2}{*}{$\omega(\mathrm{eV})$} \\
\hline & & & & $\mathrm{C}_{2} \mathrm{H}_{4}$ & $\mathrm{C}_{2} \mathrm{~F}_{4}$ & $\mathrm{C}_{2} \mathrm{H}_{4}$ & $\mathrm{C}_{2} \mathrm{~F}_{4}$ & $\mathrm{C}_{2} \mathrm{H}_{4}$ & $\mathrm{C}_{2} \mathrm{~F}_{4}$ & \\
\hline \multirow{5}{*}{ 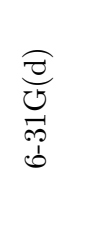 } & 1 & 0.623 & 0.631 & 0.000 & 0.000 & 0.008 & 16.769 & 0.004 & 7.172 & 7.177 \\
\hline & 2 & 0.882 & 0.958 & 0.000 & 0.000 & 3.918 & -0.166 & 7.868 & 0.492 & 8.360 \\
\hline & 3 & 0.536 & 0.579 & 0.000 & 0.000 & 5.973 & -0.003 & 8.580 & -0.002 & 8.579 \\
\hline & 4 & 0.863 & 0.941 & 0.000 & 0.000 & 0.253 & -2.706 & 0.506 & 8.092 & 8.597 \\
\hline & 5 & 0.006 & 0.006 & -0.999 & 0.999 & 32.786 & -66.831 & 1.493 & 7.905 & 9.397 \\
\hline \multirow{5}{*}{$\begin{array}{l}\stackrel{\partial}{0} \\
+ \\
+ \\
\overrightarrow{0} \\
0 \\
0\end{array}$} & 1 & 0.351 & 0.434 & -0.023 & 0.023 & 0.162 & -47.724 & 0.043 & 6.773 & 6.815 \\
\hline & 2 & 0.411 & 0.599 & -0.007 & 0.007 & 0.052 & 2.727 & 0.023 & 6.851 & 6.873 \\
\hline & 3 & 0.775 & 0.836 & 0.023 & -0.023 & -7.163 & 0.124 & 7.551 & 0.103 & 7.655 \\
\hline & 4 & 0.241 & 0.406 & 0.066 & -0.066 & -17.975 & 0.784 & 7.606 & 0.057 & 7.663 \\
\hline & 5 & 0.240 & 0.459 & -0.101 & 0.101 & 0.736 & -35.382 & 0.112 & 7.890 & 8.001 \\
\hline \multirow{5}{*}{ 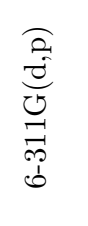 } & 1 & 0.604 & 0.630 & -0.002 & 0.002 & 0.020 & 15.736 & 0.009 & 7.123 & 7.132 \\
\hline & 2 & 0.864 & 0.944 & 0.000 & 0.000 & 2.700 & -0.037 & 7.948 & 0.128 & 8.076 \\
\hline & 3 & 0.556 & 0.609 & 0.000 & 0.000 & 5.102 & 0.001 & 8.316 & 0.001 & 8.317 \\
\hline & 4 & 0.385 & 0.412 & 0.018 & -0.018 & -11.188 & 0.426 & 8.445 & 0.088 & 8.532 \\
\hline & 5 & 0.853 & 0.933 & 0.000 & 0.000 & 0.049 & -2.701 & 0.134 & 8.415 & 8.549 \\
\hline \multirow{5}{*}{ 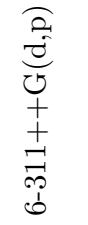 } & 1 & 0.243 & 0.439 & -0.029 & 0.029 & 0.168 & -48.219 & 0.030 & 6.812 & 6.842 \\
\hline & 2 & 0.306 & 0.600 & -0.010 & 0.010 & 0.057 & 3.162 & 0.022 & 6.868 & 6.891 \\
\hline & 3 & 0.211 & 0.319 & 0.042 & -0.042 & -21.221 & 0.349 & 7.156 & 0.035 & 7.191 \\
\hline & 4 & 0.780 & 0.847 & 0.021 & -0.021 & -6.146 & 0.107 & 7.517 & 0.096 & 7.613 \\
\hline & 5 & 0.175 & 0.340 & 0.055 & -0.055 & -20.918 & 0.417 & 7.720 & 0.098 & 7.818 \\
\hline
\end{tabular}

Table S10: ESP, FBH, and Becke fragment charges $\left(Q_{A}\right), \mathrm{FBH}$ and Becke fragment excitation energies $\left(\omega_{A}\right)$ for the lowest local excitations and charge-transfer excitations of three $\mathrm{C}_{2} \mathrm{H}_{4}-\mathrm{C}_{2} \mathrm{~F}_{4}$ configurations. Obtained from LR-TDDFT calculations using the PBE0 functional and 6-31G(d) basis set.

\begin{tabular}{|c|c|c|c|c|c|c|c|c|c|c|c|}
\hline \multirow{2}{*}{ Configuration } & \multirow{2}{*}{ ES\# } & \multicolumn{2}{|c|}{$Q_{A}^{\mathrm{ESP}}$ (a.u.) } & \multicolumn{2}{|c|}{$Q_{A}^{\mathrm{FBH}}$ (a.u.) } & \multicolumn{2}{|c|}{$Q_{A}^{\text {Becke }}$ (a.u.) } & \multicolumn{2}{|c|}{$\omega_{A}^{\mathrm{FBH}}(\mathrm{eV})$} & \multicolumn{2}{|c|}{$\omega_{A}^{\text {Becke }}(\mathrm{eV})$} \\
\hline & & $\mathrm{C}_{2} \mathrm{H}_{4}$ & $\mathrm{C}_{2} \mathrm{~F}_{4}$ & $\mathrm{C}_{2} \mathrm{H}_{4}$ & $\mathrm{C}_{2} \mathrm{~F}_{4}$ & $\mathrm{C}_{2} \mathrm{H}_{4}$ & $\mathrm{C}_{2} \mathrm{~F}_{4}$ & $\mathrm{C}_{2} \mathrm{H}_{4}$ & $\mathrm{C}_{2} \mathrm{~F}_{4}$ & $\mathrm{C}_{2} \mathrm{H}_{4}$ & $\mathrm{C}_{2} \mathrm{~F}_{4}$ \\
\hline $\bar{F}$ & 2 & 0.006 & -0.006 & 0.000 & 0.000 & 0.000 & 0.000 & -0.003 & 7.129 & -0.002 & 7.128 \\
\hline P1 & 1 & -0.041 & 0.041 & -0.010 & 0.010 & -0.010 & 0.010 & 0.026 & 7.074 & 0.022 & 7.078 \\
\hline P2 & 1 & 0.019 & -0.019 & -0.001 & 0.001 & -0.001 & 0.001 & 0.005 & 7.121 & 0.004 & 7.123 \\
\hline $\mathbf{F}$ & 1 & -0.967 & 0.967 & -0.997 & 0.997 & -0.997 & 0.997 & 0.315 & 6.698 & 0.307 & 6.706 \\
\hline P1 & 2 & -1.016 & 1.016 & -0.990 & 0.990 & -0.988 & 0.988 & 0.426 & 6.819 & 0.423 & 6.821 \\
\hline P2 & 2 & -0.964 & 0.964 & -0.999 & 0.999 & -0.997 & 0.997 & 0.466 & 6.835 & 0.463 & 6.839 \\
\hline
\end{tabular}




\section{Geometry of $\mathrm{C}_{2} \mathrm{H}_{4}-\mathrm{C}_{2} \mathrm{~F}_{4}$ Complexes}

Energy values (in Hartree) and nuclear coordinates (in $\AA$ ) of $\mathrm{C}_{2} \mathrm{H}_{4}-\mathrm{C}_{2} \mathrm{~F}_{4}$ configurations, whose monomer geometries were optimized on the $\omega \mathrm{B} 97 \mathrm{X}-\mathrm{D} / 6-311++\mathrm{G}(\mathrm{d}, \mathrm{p})$ level of theory.

F

$-554.0963807$

$\begin{array}{lr}\mathrm{C} & 0.6628906040 \\ \mathrm{C} & -0.6628906040 \\ \mathrm{H} & 1.2317033864 \\ \mathrm{H} & 1.2317033864 \\ \mathrm{H} & -1.2317033864 \\ \mathrm{H} & -1.2317033864 \\ \mathrm{C} & 0.6595916614 \\ \mathrm{C} & -0.6595916614 \\ \mathrm{~F} & 1.3822221343 \\ \mathrm{~F} & 1.3822221343 \\ \mathrm{~F} & -1.382221343 \\ \mathrm{~F} & -1.3822221343\end{array}$

P1

12

$-554.0965940$

$\begin{array}{lr}\text { C } & 0.6628906040 \\ \text { C } & -0.6628906040 \\ \text { H } & 1.2317033864 \\ \text { H } & 1.2317033864 \\ \text { H } & -1.2317033864 \\ \text { H } & -1.2317033864 \\ \text { C } & 0.6595916614 \\ \text { C } & -0.6595916614 \\ \text { F } & 1.3822221343 \\ \text { F } & 1.382221343 \\ \text { F } & -1.3822221343 \\ \text { F } & -1.382221343\end{array}$

$-2.5000000000$

$-2.5000000000$

$-1.5758714122$

$-3.4241285878$

$-1.5758714122$

$-3.4241285878$

2.5000000000

2.5000000000

3.5961774622

1. 4038225378

1.4038225378

3. 5961774622

0.0000000000

0.0000000000

0.0000000000

0.0000000000

0.0000000000

0.0000000000

0.0000000000

0.0000000000

0.0000000000

0.0000000000

0.0000000000

0.0000000000

P2

12

$-554.0959918$

$\begin{array}{ll}\text { C } & -2.5000000000 \\ \text { C } & -3.8257812080 \\ \text { H } & -1.9311872176 \\ \text { H } & -1.9311872176 \\ \text { H } & -4.3945939904 \\ \text { H } & -4.3945939904 \\ \text { C } & 3.8191833228 \\ \text { C } & 2.5000000000 \\ \text { F } & 4.5418137957 \\ \text { F } & 4.5418137957 \\ \text { F } & 1.7773695271 \\ \text { F } & 1.7773695271\end{array}$

0.0000000000

0.0000000000

0.0000000000

0.0000000000

0.9241285878

0.0000000000

$-0.9241285878$

0.9241285878

0.0000000000

0.0000000000

$\begin{array}{ll}-0.9241285878 & 0.0000000000\end{array}$

$0.0000000000 \quad 0.0000000000$

$0.0000000000 \quad 0.0000000000$

$\begin{array}{ll}1.0961774622 & 0.0000000000\end{array}$

$-1.0961774622$

0.0000000000

$-1.0961774622$

0.0000000000

1.0961774622

0.0000000000 


\section{Geometry of OLH-water Complexes}

Energy values (in Hartree) and optimized nuclear coordinates (in $\AA$ ) of OLH-water configurations using the $\omega \mathrm{B} 97 \mathrm{X}-\mathrm{D} / 6-311++\mathrm{G}(\mathrm{d}, \mathrm{p})$ level of theory.

\begin{tabular}{|c|c|c|c|}
\hline \multicolumn{4}{|c|}{ HB1 } \\
\hline \\
\hline \multicolumn{4}{|c|}{-1517.3893302} \\
\hline 0 & 4.2538611198 & -1.7102968078 & -0.1350976023 \\
\hline $\mathrm{C}$ & 3.3964102437 & -0.8640460222 & -0.0859406977 \\
\hline $\mathrm{N}$ & 2.0273555376 & -1.1458831479 & -0.0973289914 \\
\hline C & 1.3242793726 & -0.0708136003 & -0.0278193880 \\
\hline $\mathrm{S}$ & 2.1176375128 & 1.4902628698 & 0.0622830011 \\
\hline $\mathrm{C}$ & 3.7077245615 & 0.6328554136 & -0.0052917195 \\
\hline $\mathrm{H}$ & 4.3138184598 & 0.8368822411 & 0.8777987212 \\
\hline $\mathrm{H}$ & 4.2834701088 & 0.9340393659 & -0.8810678458 \\
\hline $\mathrm{C}$ & -0.1353073011 & -0.1142940247 & -0.0213642704 \\
\hline $\mathrm{S}$ & -0.9789467739 & -1.6479280033 & -0.1202116923 \\
\hline $\mathrm{N}$ & -0.8653056269 & 0.9466227640 & 0.0560134334 \\
\hline $\mathrm{C}$ & -3.7741242270 & -1.2532458443 & -0.0762464236 \\
\hline $\mathrm{C}$ & -2.4713989033 & -0.7633500956 & -0.0506952797 \\
\hline $\mathrm{C}$ & -2.1987357592 & 0.6160598787 & 0.0430297164 \\
\hline $\mathrm{C}$ & -3.2599006526 & 1.5252024173 & 0.1151242163 \\
\hline $\mathrm{C}$ & -4.5510605475 & 1.0484584333 & 0.0915766709 \\
\hline $\mathrm{C}$ & -4.8070093427 & -0.3337940158 & -0.0042851212 \\
\hline 0 & -6.0716069925 & -0.8218348565 & -0.0301146719 \\
\hline $\mathrm{H}$ & -3.9986916083 & -2.3094071051 & -0.1498797088 \\
\hline $\mathrm{H}$ & -3.0518198573 & 2.5854334539 & 0.1897401919 \\
\hline $\mathrm{H}$ & -5.3849462344 & 1.7411819787 & 0.1483214212 \\
\hline $\mathrm{H}$ & -6.7047270793 & -0.1045243627 & 0.0268935355 \\
\hline 0 & 6.6343604358 & -0.2168495670 & 0.1563320983 \\
\hline $\mathrm{H}$ & 6.0017953469 & -0.9397810477 & 0.0343875855 \\
\hline $\mathrm{H}$ & 7.4890590282 & -0.6323942618 & 0.2664158559 \\
\hline \multicolumn{4}{|c|}{ HB2 } \\
\hline \multicolumn{4}{|c|}{25} \\
\hline \multicolumn{4}{|c|}{-1517.3851365} \\
\hline 0 & 5.0259513484 & -2.0014583322 & -0.0316786647 \\
\hline $\mathrm{C}$ & 4.2870055691 & -1.0599050082 & -0.0195902268 \\
\hline $\mathrm{N}$ & 2.8819536360 & -1.1520773836 & -0.0226945452 \\
\hline $\mathrm{C}$ & 2.3299593991 & 0.0045091464 & -0.0092913001 \\
\hline $\mathrm{S}$ & 3.3252712664 & 1.4573053635 & 0.0102155570 \\
\hline $\mathrm{C}$ & 4.7872245795 & 0.3941 & 0.0016537620 \\
\hline $\mathrm{H}$ & 5.3923123267 & 0.5531723007 & 0.8943126994 \\
\hline $\mathrm{H}$ & 5.4005646549 & 0.5775573914 & -0.8805935767 \\
\hline $\mathrm{C}$ & 0.8766259455 & 0.1614966296 & -0.0095077730 \\
\hline $\mathrm{S}$ & -0.1660211427 & -1.2461002185 & -0.0233549430 \\
\hline $\mathrm{N}$ & 0.2997054642 & 1.3153765189 & 0.0013697439 \\
\hline $\mathrm{C}$ & -2.8810978010 & -0.4791167950 & -0.0178181022 \\
\hline $\mathrm{C}$ & -1.5241528495 & -0.1649122829 & -0.0148740276 \\
\hline $\mathrm{C}$ & -1.0672891776 & 1.1677582022 & -0.0013652846 \\
\hline $\mathrm{C}$ & -1.9937927795 & 2.2153360921 & 0.0095735641 \\
\hline $\mathrm{C}$ & -3.3381914072 & 1.9163637961 & 0.0038500803 \\
\hline $\mathrm{C}$ & -3.7720016050 & 0.5786566290 & -0.0106176172 \\
\hline 0 & -5.1051569251 & 0.2750575801 & -0.0211521256 \\
\hline $\mathrm{H}$ & -3.2505920093 & -1.4982578426 & -0.0204390721 \\
\hline
\end{tabular}




\begin{tabular}{|c|c|c|c|}
\hline $\mathrm{H}$ & -1.6431137918 & 3.2398060457 & 0.0209210291 \\
\hline $\mathrm{H}$ & -4.0705213241 & 2.7177214825 & 0.0090674630 \\
\hline $\mathrm{H}$ & -5.6308461690 & 1.0720591820 & 0.0620210063 \\
\hline 0 & -5.3641244758 & -2.6073825078 & 0.1204771076 \\
\hline $\mathrm{H}$ & -5.5810960020 & -1.6704576957 & 0.0619820363 \\
\hline $\mathrm{H}$ & -5.9193651539 & -3.0449055372 & -0.5245561629 \\
\hline \multicolumn{4}{|c|}{$\mathrm{T} 1.6$} \\
\hline \multicolumn{4}{|c|}{25} \\
\hline \multicolumn{4}{|c|}{-1517.3649052} \\
\hline 0 & -4.7930287203 & 1.5941094205 & 0.1280499006 \\
\hline $\mathrm{C}$ & -3.9435865972 & 0.7517553082 & 0.0922975267 \\
\hline $\mathrm{N}$ & -2.5601893057 & 1.0176468787 & 0.0884265343 \\
\hline $\mathrm{C}$ & -1.8707695535 & -0.0622449643 & 0.0490702525 \\
\hline $\mathrm{S}$ & -2.6766812938 & -1.6253285409 & 0.0057999983 \\
\hline $\mathrm{C}$ & -4.2597126006 & -0.7518015777 & 0.0466498860 \\
\hline $\mathrm{H}$ & -4.8347924661 & -1.0267494424 & 0.9309521335 \\
\hline $\mathrm{H}$ & -4.8500930330 & -0.9697932719 & -0.8433737380 \\
\hline $\mathrm{C}$ & -0.4091348319 & -0.0346182506 & 0.0421194685 \\
\hline $\mathrm{S}$ & 0.4458955352 & 1.4974835522 & 0.0859023645 \\
\hline $\mathrm{N}$ & 0.3117963693 & -1.1019367688 & 0.0037510161 \\
\hline $\mathrm{C}$ & 3.2400505115 & 1.0788022798 & 0.1056610113 \\
\hline $\mathrm{C}$ & 1.9303205691 & 0.5999987520 & 0.0505104515 \\
\hline $\mathrm{C}$ & 1.6470148267 & -0.7821615018 & 0.0093919767 \\
\hline $\mathrm{C}$ & 2.7030881473 & -1.7026849679 & 0.0265958224 \\
\hline $\mathrm{C}$ & 3.9993285342 & -1.2368589283 & 0.0790654603 \\
\hline $\mathrm{C}$ & 4.2691419939 & 0.1478199993 & 0.1184032553 \\
\hline 0 & 5.5302595850 & 0.6256924374 & 0.2038209922 \\
\hline $\mathrm{H}$ & 3.4719340383 & 2.1337511749 & 0.1712485626 \\
\hline $\mathrm{H}$ & 2.4864778886 & -2.7629689814 & 0.0354238488 \\
\hline $\mathrm{H}$ & 4.8231418407 & -1.9400358178 & 0.1341814217 \\
\hline $\mathrm{H}$ & 6.1520619473 & -0.0953473168 & 0.3166390784 \\
\hline $\mathrm{H}$ & 2.9196211740 & -0.3555486229 & 1.6841345732 \\
\hline 0 & 2.9124016296 & -0.4777833107 & 2.6509028988 \\
\hline $\mathrm{H}$ & 2.5461490113 & 0.3323871612 & 3.0054092039 \\
\hline \multicolumn{4}{|c|}{ T1.7 } \\
\hline \multicolumn{4}{|c|}{25} \\
\hline \multicolumn{4}{|c|}{-1517.3702160} \\
\hline 0 & -4.7955588337 & 1.5942681066 & 0.1207736146 \\
\hline $\mathrm{C}$ & -3.9458103010 & 7521828067 & 0.0863554274 \\
\hline $\mathrm{N}$ & -2.5624496420 & 1.0185782990 & 0.0841115317 \\
\hline C & -1.8726395865 & -0.0610205586 & 0.0451429217 \\
\hline $\mathrm{S}$ & -2.6779774173 & -1.6244548722 & 0.0013729286 \\
\hline $\mathrm{C}$ & -4.2613459832 & -0.7514966895 & 0.0409266175 \\
\hline $\mathrm{H}$ & -4.8366808273 & -1.0263481110 & 0.9251138257 \\
\hline $\mathrm{H}$ & -4.8513161715 & -0.9700489235 & -0.8492154203 \\
\hline $\mathrm{C}$ & -0.4109046876 & -0.0332429320 & 0.0384745670 \\
\hline $\mathrm{s}$ & 0.4445454891 & 1.4984717655 & 0.0825523376 \\
\hline $\mathrm{N}$ & 0.3095831484 & -1.1008504576 & 0.0005495449 \\
\hline $\mathrm{C}$ & 3.2383471771 & 1.0788304120 & 0.0953702795 \\
\hline $\mathrm{C}$ & 1.9289818219 & 0.6001947097 & 0.0475609229 \\
\hline $\mathrm{C}$ & 1.6453788987 & -0.7812954558 & 0.0065322078 \\
\hline $\mathrm{C}$ & 2.7004751955 & -1.7019662586 & 0.0171444854 \\
\hline $\mathrm{C}$ & 3.9967404977 & -1.2364029162 & 0.0633689901 \\
\hline $\mathrm{C}$ & 4.2667675921 & 0.1477671107 & 0.1008820777 \\
\hline 0 & 5.5293404089 & 0.6254821159 & 0.1710477277 \\
\hline $\mathrm{H}$ & 3.4710188436 & 2.1340491245 & 0.1541219872 \\
\hline $\mathrm{H}$ & 2.4836859210 & -2.7623211380 & 0.0206186998 \\
\hline
\end{tabular}




\begin{tabular}{|c|c|c|c|}
\hline $\mathrm{H}$ & 4.8214125529 & -1.9394843362 & 0.1076784087 \\
\hline $\mathrm{H}$ & 6.1524277850 & -0.0958209687 & 0.2745542877 \\
\hline $\mathrm{H}$ & 2.9359488118 & -0.3568752410 & 1.7696232561 \\
\hline 0 & 2.9281144718 & -0.4808407006 & 2.7320471916 \\
\hline $\mathrm{H}$ & 2.5526100347 & 0.3262298088 & 3.0843254814 \\
\hline \multicolumn{4}{|c|}{$\mathrm{T} 1.8$} \\
\hline \multicolumn{4}{|c|}{25} \\
\hline \multicolumn{4}{|c|}{-1517.3742191} \\
\hline 0 & -4.7968532131 & 1.5949258404 & 0.1184197734 \\
\hline $\mathrm{C}$ & -3.9470461237 & 0.7529597990 & 0.0831815456 \\
\hline $\mathrm{N}$ & -2.5636671113 & 1.0195929632 & 0.0795659686 \\
\hline $\mathrm{C}$ & -1.8737668599 & -0.0599096642 & 0.0406064958 \\
\hline $\mathrm{S}$ & -2.6789034001 & -1.6234927394 & -0.0018750736 \\
\hline $\mathrm{C}$ & -4.2623927878 & -0.7507682652 & 0.0379376727 \\
\hline $\mathrm{H}$ & -4.8376114015 & -1.0256645487 & 0.9221717339 \\
\hline $\mathrm{H}$ & -4.8523929855 & -0.9694168588 & -0.8521716536 \\
\hline $\mathrm{C}$ & -0.4119345297 & -0.0321278506 & 0.0329180485 \\
\hline $\mathrm{S}$ & 0.4438482500 & 1.4994007964 & 0.0753794164 \\
\hline $\mathrm{N}$ & 0.3082052793 & -1.0999611371 & -0.0037577130 \\
\hline $\mathrm{C}$ & 3.2375880945 & 1.0788138977 & 0.0827550972 \\
\hline $\mathrm{C}$ & 1.9284288743 & 0.6005242826 & 0.0412740847 \\
\hline $\mathrm{C}$ & 1.6444866690 & -0.7806061013 & 0.0017438672 \\
\hline $\mathrm{C}$ & 2.6988852950 & -1.7014426106 & 0.0059827358 \\
\hline $\mathrm{C}$ & 3.9953652089 & -1.2362025678 & 0.0464164310 \\
\hline $\mathrm{C}$ & 4.2654634735 & 0.1476094486 & 0.0834800627 \\
\hline 0 & 5.5289781579 & 0.6253587424 & 0.1410915681 \\
\hline $\mathrm{H}$ & 3.4710305073 & 2.1342166627 & 0.1353732787 \\
\hline $\mathrm{H}$ & 2.4817554629 & -2.7618207042 & 0.0044147170 \\
\hline $\mathrm{H}$ & 4.8206490362 & -1.9393279535 & 0.0790099207 \\
\hline $\mathrm{H}$ & 6.1526408892 & -0.0953523035 & 0.2452023944 \\
\hline $\mathrm{H}$ & 2.9476613567 & -0.3688964003 & 1.8538059641 \\
\hline 0 & 2.9455946340 & -0.4779137081 & 2.8149313048 \\
\hline $\mathrm{H}$ & 2.5446824240 & 0.3230856804 & 3.1531762590 \\
\hline \multicolumn{4}{|c|}{$\mathrm{T} 1.9$} \\
\hline \multicolumn{4}{|c|}{25} \\
\hline \multicolumn{4}{|c|}{-1517.3771603} \\
\hline 0 & -4.7968675731 & 1.5969244894 & 0.1115908846 \\
\hline $\mathrm{C}$ & -3.9471539640 & 0.7547940529 & 0.0781467068 \\
\hline $\mathrm{N}$ & -2.5637400985 & 1.0212339032 & 0.0752939694 \\
\hline $\mathrm{C}$ & -1.8739343005 & -0.0583532008 & 0.0375620770 \\
\hline $\mathrm{S}$ & -2.6793094404 & -1.6219163055 & -0.0037176884 \\
\hline C & -4.2626778889 & -0.7489462961 & 0.0348870850 \\
\hline $\mathrm{H}$ & -4.8378797157 & -1.0225625729 & 0.9195481137 \\
\hline $\mathrm{H}$ & -4.8528097419 & -0.9688068439 & -0.8548252038 \\
\hline $\mathrm{C}$ & -0.4120996874 & -0.0308128581 & 0.0297892076 \\
\hline $\mathrm{S}$ & 0.4442160741 & 1.5004275090 & 0.0706651510 \\
\hline $\mathrm{N}$ & 0.3077156535 & -1.0989174518 & -0.0062854634 \\
\hline C & 3.2375640202 & 1.0794057968 & 0.0697182360 \\
\hline C & 1.9287570292 & 0.6008588306 & 0.0367250656 \\
\hline $\mathrm{C}$ & 1.6443264470 & -0.7799189729 & -0.0019549414 \\
\hline $\mathrm{C}$ & 2.6984471837 & -1.7007093353 & -0.0034989065 \\
\hline $\mathrm{C}$ & 3.9950118825 & -1.2352781115 & 0.0297273436 \\
\hline $\mathrm{C}$ & 4.2652175704 & 0.1483418823 & 0.0640001228 \\
\hline 0 & 5.5292886489 & 0.6262094931 & 0.1093128494 \\
\hline $\mathrm{H}$ & 3.4712834828 & 2.1350799783 & 0.1156573172 \\
\hline $\mathrm{H}$ & 2.4817406969 & -2.7612351056 & -0.0080874762 \\
\hline $\mathrm{H}$ & 4.8208550826 & -1.9382705915 & 0.0528557460 \\
\hline
\end{tabular}




\begin{tabular}{|c|c|c|c|}
\hline $\mathrm{H}$ & 6.1544745760 & -0.0945954917 & 0.2029486309 \\
\hline $\mathrm{H}$ & 2.9562608170 & -0.3850780958 & 1.9391950678 \\
\hline 0 & 2.9622636145 & -0.4750309404 & 2.8998746214 \\
\hline $\mathrm{H}$ & 2.5197448310 & 0.3107409384 & 3.2219053837 \\
\hline \multicolumn{4}{|c|}{$\mathrm{T} 2.0$} \\
\hline \multicolumn{4}{|c|}{25} \\
\hline \multicolumn{4}{|c|}{-1517.3792127} \\
\hline 0 & -4.7958109488 & 1.5994521710 & 0.1159949457 \\
\hline $\mathrm{C}$ & -3.9465898952 & 0.7570321045 & 0.0791366150 \\
\hline $\mathrm{N}$ & -2.5629704137 & 1.0229013275 & 0.0749881151 \\
\hline $\mathrm{C}$ & -1.8737414434 & -0.0569362822 & 0.0351588288 \\
\hline $\mathrm{S}$ & -2.6798016947 & -1.6200724728 & -0.0078915815 \\
\hline $\mathrm{C}$ & -4.2627924343 & -0.7464710380 & 0.0324964653 \\
\hline $\mathrm{H}$ & -4.8385167305 & -1.0218936253 & 0.9162198349 \\
\hline $\mathrm{H}$ & -4.8525568633 & -0.9639512233 & -0.8580696431 \\
\hline $\mathrm{C}$ & -0.4118070575 & -0.0298396414 & 0.0262855317 \\
\hline $\mathrm{S}$ & 0.4448260510 & 1.5012244491 & 0.0657021497 \\
\hline $\mathrm{N}$ & 0.3076339244 & -1.0982582224 & -0.0092123827 \\
\hline $\mathrm{C}$ & 3.2377369931 & 1.0797384525 & 0.0576616036 \\
\hline $\mathrm{C}$ & 1.9293966431 & 0.6011483514 & 0.0316933418 \\
\hline $\mathrm{C}$ & 1.6445903777 & -0.7793892411 & -0.0056562399 \\
\hline $\mathrm{C}$ & 2.6981447968 & -1.7002252800 & -0.0117990616 \\
\hline $\mathrm{C}$ & 3.9951807319 & -1.2347245886 & 0.0163437312 \\
\hline $\mathrm{C}$ & 4.2653256116 & 0.1487603764 & 0.0478748764 \\
\hline 0 & 5.5297676302 & 0.6272060702 & 0.0820648661 \\
\hline $\mathrm{H}$ & 3.4718930773 & 2.1355163930 & 0.0991483349 \\
\hline $\mathrm{H}$ & 2.4813210081 & -2.7608007411 & -0.0182635215 \\
\hline $\mathrm{H}$ & 4.8211632324 & -1.9378926706 & 0.0328705594 \\
\hline $\mathrm{H}$ & 6.1566315597 & -0.0934416407 & 0.1650418543 \\
\hline $\mathrm{H}$ & 3.0064570805 & -0.4208423347 & 2.0248812018 \\
\hline 0 & 2.9744591403 & -0.4574765578 & 2.9869204814 \\
\hline $\mathrm{H}$ & 2.4507548233 & 0.3028205642 & 3.2414429934 \\
\hline \multicolumn{4}{|c|}{$\mathrm{T} 2.1$} \\
\hline \multicolumn{4}{|c|}{25} \\
\hline \multicolumn{4}{|c|}{-1517.3806181} \\
\hline 0 & -4.7915291530 & 1.6011037138 & 0.1067271921 \\
\hline $\mathrm{C}$ & -3.9418644182 & 0.7589026106 & 0.0751581744 \\
\hline $\mathrm{N}$ & -2.5584517092 & 1.0255223246 & 0.0661440469 \\
\hline $\mathrm{C}$ & -1.8685971699 & -0.0541110863 & 0.0322003096 \\
\hline $\mathrm{S}$ & -2.6738980271 & -1.6180615542 & 0.0028485902 \\
\hline $\mathrm{C}$ & -4.2573105527 & -0.7451053664 & 0.0416304741 \\
\hline $\mathrm{H}$ & -4.8295770056 & -1.0137300490 & 0.9297158820 \\
\hline $\mathrm{H}$ & -4.8503052712 & -0.9702619077 & -0.8448462642 \\
\hline $\mathrm{C}$ & -0.4067291796 & -0.0262920921 & 0.0189812075 \\
\hline $\mathrm{S}$ & 0.4494724423 & 1.5051619002 & 0.0471696316 \\
\hline $\mathrm{N}$ & 0.3130165947 & -1.0947567947 & -0.0117611159 \\
\hline C & 3.2424447544 & 1.0846369658 & 0.0313473585 \\
\hline $\mathrm{C}$ & 1.9346962538 & 0.6053076721 & 0.0142902655 \\
\hline $\mathrm{C}$ & 1.6501774768 & -0.7754728907 & -0.0140928344 \\
\hline $\mathrm{C}$ & 2.7043520012 & -1.6960374644 & -0.0201721358 \\
\hline $\mathrm{C}$ & 4.0009205712 & -1.2295162560 & 0.0002595819 \\
\hline $\mathrm{C}$ & 4.2701671461 & 0.1541616333 & 0.0227516099 \\
\hline 0 & 5.5347033476 & 0.6331720970 & 0.0444434234 \\
\hline $\mathrm{H}$ & 3.4760659813 & 2.1408633995 & 0.0627745411 \\
\hline $\mathrm{H}$ & 2.4880780579 & -2.7568144607 & -0.0235426314 \\
\hline $\mathrm{H}$ & 4.8276433441 & -1.9320195355 & 0.0112802593 \\
\hline $\mathrm{H}$ & 6.1624419123 & -0.0866320158 & 0.1278205766 \\
\hline
\end{tabular}


$2.9461494127 \quad-0.4527285337$

2. 9703410905

$-0.4625130114$

3. 0658010651

2. 3982872997

0.2588054017

3. 3297943176 